\title{
Pathogenic Mycoplasma Infections in Chronic Illnesses: General Considerations in Selecting Conventional and Integrative Treatments
}

\author{
Garth L. Nicolson \\ Department of Molecular Pathology, The Institute for Molecular Medicine, Huntington Beach, California, USA \\ Email: gnicolson@immed.org
}

How to cite this paper: Nicolson, G.L. (2019) Pathogenic Mycoplasma Infections in Chronic Illnesses: General Considerations in Selecting Conventional and Integrative Treatments. International Journal of Clinical Medicine, 10, 477-522.

https://doi.org/10.4236/ijcm.2019.1010041

Received: September 12, 2019

Accepted: October 12, 2019

Published: October 15, 2019

Copyright $\odot 2019$ by author(s) and Scientific Research Publishing Inc. This work is licensed under the Creative Commons Attribution International License (CC BY 4.0).

http://creativecommons.org/licenses/by/4.0/

\begin{abstract}
The presence of pathogenic mycoplasmas in various chronic illnesses and their successful suppression using conventional and integrative medicine approaches are reviewed. Evidence gathered over the last three decades has demonstrated the presence of pathogenic mycoplasma species in the blood, body fluids and tissues from patients with a variety of chronic clinical conditions: atypical pneumonia, asthma and other respiratory conditions; oral cavity infections; urogenital conditions; neurodegenerative and neurobehavioral diseases; autoimmune diseases; immunosuppressive diseases; inflammatory diseases; and illnesses and syndromes of unknown origin, such as fatiguing illnesses. Only recently have these small intracellular bacteria received attention as possible causative agents, cofactors or opportunistic infections or co-infections in these and other conditions. Their clinical management is often inadequate, primarily because of missed diagnosis, under- and inadequate treatment and the presence of persister or dormant microorganisms due to biofilm, resistence and other mechanisms. Pathogenic Mycoplasma species infections have been suppressed slowly by anti-microbial and integrative treatments, resulting in gradual reductions in morbidity, but not in every patient. Even if mycoplasmas are not a cause or an initial trigger for many chronic illnesses, they appear to play important roles in the inception, progression, morbidity and relapse of chronic illnesses in rather large patient subsets. Ignoring such infections can result in failure to achieve eventual patient recovery, even with application of potentially curative treatments.
\end{abstract}

\section{Keywords}

Chronic Diseases, Infections, Antibiotics, Herbel Therapy, Immune Enhancement, Membrane Lipid Replacement, Mycoplasma, Natural Supplements, Integrative Medicine 


\section{Introduction}

Mycoplasmas belong to the class Mollicutes, and they are considered the smallest free-living prokaryocytes capable of self-replication [1] [2]. There are more than 200 bacterial microorganisms that belong to the genus of Mycoplasma, and the more than two dozen pathogenic species found in humans are typified by: 1) lack of an external cell wall; 2) obligate parasitic behavior; 3) intracellular growth; and 4) the loss of many of their genes due to reductive evolution [2] [3] [4]. Mycoplasmas are widely distributed in nature, where they are often found attached to the external surfaces of cells or residing and replicating inside host cells [1] [2].

It has been only fairly recently that mycoplasmas have been identified as important pathogens in humans, animals, plants and insects [1] [3] [5] [6]. There is evidence in humans that pathogenic mycoplasmas are associated with certain chronic diseases where they could function as causative agents, cofactors or opportunistic infections that cause patient morbidity [5] [6] [7]. For example, pathogenic mycoplasmas in humans are often associated with respiratory infections, urogenital infections, fatiguing illnesses, autoimmune diseases, neurodegenerative and neurobehavioral diseases and complications affecting the central nervous system, cardiac infections, oral infections, peridontal diseases, sexually transmitted diseases and systemic infections found in various solid cancers and leukemias and immunosuppressive diseases, such as HIV-AIDS [5] [6] [7].

Although various mycoplasmas are commonly found as commensals in the oral cavity and at other superficial sites [3], certain pathogenic species appear to cause morbidity when they penetrate into the blood and spread to and colonize various tissues [2] [5] [6] [7]. For example, Mycoplasma hominis and Ureaplasma urealyticum are common inhabitants of the human genital tract, but they can play an etiologic role in pyelonephritis, pelvic inflammatory disease as well as in post-abortion and post-partum fevers [3] [7] [8] [9] [10]. Furthermore, there are reports of mycoplasmas causing serious acute infections, such as septicemia, septic arthritis, neonatal meningitis and encephalitis [2] [6] [7] [11]. As an example of their pathogenic potential in mammals, it was shown that $M$. fermentans can cause severe neurological signs and symptoms after injection into the cerebral fluid of rats [12] [13]. Although still a subject of intense discussion, several pathogenic mycoplasma species have been proposed to be etiologic agents or cofactors in various chronic diseases of man [1] [2] [3] [5] [6] [7]. This will be discussed briefly in the next sections.

Mycoplasmas contain the smallest known self-replicating genomes, and they have an unusually low G + C content (25\% - 33\%) [1] [4]. With their limited genomes mycoplasmas have provided researchers with a simple model for the identification of the minimal gene set required for the survival and growth of a free-living bacterium [14] [15]. The small genomes of $M$. genitalium and $M$. pneumoniae encode approximately 400 - 600 proteins, compared to about 4000 in E. coli [16]. Furthermore, mycoplasmas still maintain all of the essential genes 
for replication, transcription, and translation as well as the minimal number of energy metabolism genes needed for their parasitic modes of life. They can do this with a core number of slightly less than 400 essential genes [17].

Essentially all mycoplasmas live as parasites or commensals in various species of animals and plants, where they are usually found attached to or inside host cells [3] [4] [5]. Thus a significant number of mycoplasmal genes are devoted to encoding cell adhesion and attachment structures as well as variable membrane surface antigens to maintain parasitism and evade host immune and non-immune surveillance systems [3] [4] [5]. The adherence of mycoplasmas to specific tissue cell surfaces is a crucial step in the establishment of infections, and pathogenic mycoplasmas possess specialized structures that permit targeted cell attachment to specific host cells. For example, M. pneumoniae, which is commonly found in cases of atypical childhood pneumonia, requires a network of interactive adhesion molecules and accessory proteins for its adherence to host epithelial cells [4] [5]. The adhesion molecules must cluster at specific mycoplasma organelles in close association with cytoadherence-related accessory proteins that appear to function together and comprise a primitive membrane adhesion structure [4] [5] [18] [19].

Mycoplasmas can adapt quickly to their microenvironments. This adaptation is an important element in mycoplasma pathogenicity, and it can be attributed to their rapidly varying genomic structures and abilities to quickly change [3]. When mycoplasmas evolved and adapted to parasitic modes of life, their transformation was likely made possible by devoting many of their genes to parasitic functions. Thus the genetic evolutions of mycoplasmas have ensured rapid alterations in cell membrane characteristics, such as membrane lipid phase variations and variable regulations of distinct membrane surface proteins involved in cell colonization and host immune system avoidance. Some examples include size and sequence variations in the structural domains of surface proteins, epitope masking and demasking, and changes in protein surface presentations [20].

Mycoplasmas are known to variably express structurally heterogeneous cell surface antigens and adhesion molecules. For example, variations in the genes encoding cell surface adherence molecules, such as the variable adherence-associated (Vaa) antigen, reveal distinct patterns of mutations capable of generating multiple changes in mycoplasma cell surface antigen molecules and their antigenic size and diversity [21]. In addition, mycoplasmas can scavenge host structures, such as host glycans, for decoration of their own surface glycolipids to avoid detection [22].

Variable surface antigenic structures and rapid changes in their expression are thought to play important roles in the pathogenesis of mycoplasmal infections by providing altered epitope structures for an escape from immune responses and changes in adhesion structures. This can influence cell and tissue colonization and penetration of mucosal barriers [21] [23].

Mycoplasmas have small and unique genomes that contain repetitive and other elements, and this contributes to the variability in antigenic structures. For 
example, the genome of $M$. genitalium was recently sequenced and found to encode a number of identifiable membrane proteins as well as membrane glycolipo proteins whose sequences do not resemble previously sequenced genes [24]. For example, repeated fragments of a gene encoding a $140 \mathrm{kDa}$ adhesion lipoprotein $(\mathrm{MgPa})$ have been found, and interestingly, this lipoprotein has been localized to the tips of mycoplasma protrusions where it facilitates cell attachment and penetration [25]. Repetitive sequence elements are also variably present that do not appear to encode expressed proteins. However, recombination of these repetitive elements with other genes may explain the appearance of polymorphisms within the genes and their encoded surface proteins of different mycoplasma strains. These repetitive elements, for example in the $M$. genitalium genome, may provide a reservoir of sequences that could contribute to the variability of antigenic structures and adhesive properties found in pathogenic mycoplasmas [26].

\section{Mycoplasmas and Host Response Systems}

Pathogenic mycoplasmas can activate or suppress host response systems, and they apparently use these and other strategies to evade host immune surveillance [27]. For example, pathogenic mycoplasmas can act as immune cell suppressors/activators and inhibit or stimulate the proliferation of various lymphocyte subsets involved in memory, suppression and other activities. Pathogenic mycoplasmas can also induce B-cell differentiation and trigger the secretion of pro-inflammatory cytokines, including interleukin-1 $\beta$ (IL-1 $\beta$ ), IL-2, IL-6, IL-8, among others, tumor necrosis factor- $\alpha$ (TNF $\alpha$ ), various interferons, and granulocyte macrophage-colony stimulating factor (GM-CSF) from cells. This also occurs in vivo in patients with pathogenic mycoplasmal infections. In fact, the release of inflammatory cytokines in vivo is predictive of refractory mycoplasmal infections in children [28].

Mycoplasma-derived lipopeptides can directly stimulate host response cells, such as macrophages. Such lipoproteins have been found to be highly effective at immune stimulation similar to endotoxins derived from other bacteria [29]. Using nitric oxide release by macrophages as an indicator of immune stimulation a M. fermentans-derived lipopeptide was identified as a potent activator of macrophage function [30]. In addition, $M$. fermentans-derived lipoproteins can interfere with the interferon gamma-dependent (IFN- $\gamma$-dependent) expression of MHC class II molecules on macrophages [31].

Pathogenic mycoplasmas are also able to secret soluble factors that can activate and stimulate proliferation or inhibit the growth and differentiation of immune competent cells. For example, $M$. penetrans can induce significant proliferative responses in peripheral blood mononuclear cells, and this was found to be associated with the expression of surface markers of lymphocyte activation. The activation was observed in lymphocytes (both CD4+ and CD8+ T lymphocytes) from healthy donors as well as from HIV-infected subjects at different stages of disease progression [32]. Thus pathogenic mycoplasmas have evolved with the ability to modulate and interfere with host responses. 
The secretion of immune-modulating substances stimulated by pathogenic Mycoplasma species is an important aspect of mycoplasma immune modulation [27]. In the case of Mycoplasma fermentans a released lipoprotein can stimulate the induction of monocyte cytokines and chemokines [33]. Another example is spiralin, a well-characterized mycoplasma lipoprotein that can stimulate the in vitro proliferation of human peripheral blood mononuclear cells and murine splenocytes. This results in secretion of proinflammatory cytokines, such as TNFa, IL-1 and IL-6. Spiralin can also induce the maturation of murine B-cells. The spiralin-mediated activity appears to be similar to other immune-modulating lipoproteins secreted by other pathogenic bacteria [34]. The stimulation of various cytokines by pathogenic mycoplasmas is an important property that contributes significantly to patient morbidity.

Pathogenic mycoplasmas can evade immune recognition and destruction by undergoing rapid surface antigenic variations [7] [27]. Even with their slow intracellular growth rates, by rapidly altering their cell surface antigenic structures as well as modulating host immune responses, pathogenic mycoplasmas can evade host surveillance mechanisms [7] [27]. This helps explain the chronic nature of mycoplasmal infections and the inability of hosts to completely suppress pathogenic mycoplasmal infections via host responses that are effective against other more rapidly growing bacteria [27]. Slow-growing microorganisms like mycoplasmas use these properties to change surface antigens and hide from immune systems, a strategy that is quite unlike most rapidly growing bacteria that attempt to use their rapid proliferation rates to outpace and overwhelm host immune defenses.

Adaptations of pathogenic mycoplasmas to unique host microenvironments are usually accompanied by rapid changes in cell surface adhesion receptors (for cell binding and entry) as well as rapid structural protein changes in order to mimic host antigenic structures (antigen "mimicry"). During chronic pathogenic mycoplasma infections the size, antigenic diversity and expression of cell adhesion antigens change. For example, the divergence of variable surface antigens can affect the adherence properties of mycoplasmas and enhance their abilities to evade foreign protein recognition by host immune systems, thus contributing to their adaptive abilities and survival in their human hosts [27]. This is only one example of the abilities of mycoplasma surface antigens to promote survival and pathogenic properties [5] [7] [23] [27].

\section{Mycoplasma Toxicity and Pathogenesis}

As described briefly above, pathogenic mycoplasmas can induce host responses that result in the release of inflammatory cytokines that cause host symptoms. In addition, the severity of host symptoms during pathogenic mycoplasma infections parallels the elevated expression of inflammatory cytokines [21] [27].

Various virulence mechanisms have been implicated in the pathogenesis of mycoplasmas (reviewed in [21] [35]). For example, intracellular mycoplasmas compete for cellular nutrients and metabolites, and this can interfere with cellu- 
lar metabolism by depleting biosynthetic precursors and disrupting metabolic and synthetic pathways. Mycoplasmas secrete some of their own enzymes, such as lipases, proteases, nucleases and other enzymes, that can disrupt and interfere with host substrates, structures, enzymes and metabolic cycles [5] [21]. Mycoplasmas also have the capacity to stimulate the generation of hydrogen peroxide and superoxide radicals that damage host cellular membranes and other structures [36]. There are other possible ways that pathogenic mycoplasmas could be involved in damaging host cellular structures and normal cellular processes, such as direct membrane-membrane interactions found in cell adhesion, membrane fusion, vacuolization, and release of toxins or cytopathic molecules, but the actual molecular damage mechanisms of many of these interactions have remained elusive [21] [35]. The goal of pathogenic mycoplasmas is to hide and survive, not necessarily to kill their host, and they are very adept at achieving these goals.

One property of pathogenic mycoplasmas that can be used to directly suppress host cell responses is the initiation of apoptosis or programmed cell death of particular host cells, such as cells involved in host immune and non-immune responses [35]. One of the hallmarks of this process is host cell DNA fragmentation. For example, $M$. penetrans can induce or enhance apoptosis of peripheral mononuclear cells. The usual telltale sign of this is DNA fragmentation (typified by DNA ladder formation seen after electrophoretic separation) catalyzed by endogenous $\mathrm{Ca}^{2+}, \mathrm{Mg}^{2+}$-dependent endonucleases. In this example, an $M$. penetrans endonuclease (p40) was identified as a pathogenic mycoplasma determinant [36].

Pathogenic mycoplasma-released nucleases may also be involved in secondary necrosis, as seen in some advanced mycoplasmal infections [37]. This is indicated by the occurrence of both morphological characteristics of apoptosis (chromatin condensation) and necrosis (loss of membrane integrity with organelle swelling) [38]. In these examples, cell death was accompanied by oligonucleosomal DNA fragmentation and loss of chromosomal DNA.

Cytokine-inducing activity is a general feature of most if not all pathogenic mycoplasma species, but it appears that only some mycoplasma species can induce cell death. In the case of $M$. fermentans infections the cell death-inducing effects were not mediated by known mycoplasmal-induced cytokines, which are typically mediated by lipid-associated molecules (lipoproteins). Also, they were not accompanied by decreases in the mitochondrial trans-membrane potential or inhibited by preincubation with the antioxidant drug $\mathrm{N}$-acetylcysteine, events typically found in TNFa-mediated apoptosis. Instead, a non-lipid-associated protein (15 - $30 \mathrm{kDa})$ mediated the cytocidal effects [39].

Pathogenic mycoplasmas can cause cardiovascular and pulmonary manifestations that can result in extreme patient morbidity [35] [40]. There are several examples of this in the literature, and they have been reported as vascular occlusion due to thrombosis caused by stimulation of autoimmunity and the formation of vascular immune complexes. Vascular occlusion has been reported for 
heart, lung, kidney, brain and other organs in pathogenic mycoplasma infections [38] [40].

In addition to stimulating cell and organ death, pathogenic mycoplasmas can also release growth inhibitory molecules into their surroundings. For example, the enzyme arginine deaminase is an example of a growth-inhibitory enzyme derived from mycoplasmas that inhibits the growth of human T-cells and T-lymphoblastoid cell lines. Arginine deaminase can suppresses IL-2 production and receptor expression in T-cells stimulated by non-specific mitogens, while also inducing the morphologic features of dying cells, including the type of DNA fragmentation seen during apoptosis [41]. This enzyme has been followed in patients with community-acquired pneumonia as a possible marker for M. pneumoniae infections [42].

Pathogenic mycoplasmas can also release toxins that directly damage cells or activate innate host response systems [40]. For example, Becker et al. [43] have isolated a Mycoplasma pneumoniae-released factor, called the community-acquired respiratory distress syndrome toxin (CARDS), an ADP-ribosylating and vacuolating cytotoxin. This pathogenic mycoplasma toxin activates the NLRP3 inflammasome complex and causes subsequent release of IL-1 and hyper-inflammation that can cause tissue damage and other pathologies. The mycoplasma toxin appears to cause pulmonary inflammation, cytokine release, and significant airway dysfunction and may be responsible, in part, for respiratory failure and fatal outcomes found in acute M. pneumoniae infections [44].

\section{Mycoplasmal Infections in Various Acute and Chronic Illnesses}

Pathogenic mycoplasmal infections have been found in a variety of human diseases and conditions [45] [46] [47]. First, pathogenic mycoplasmas have been detected at higher incidence in blood and tissue specimens obtained from patients with various chronic illnesses compared to comparable healthy controls. Since the possible involvement of mycoplasmas in the cause and pathogenesis of chronic illnesses have not been firmly established, it remains uncertain whether such mycoplasmas are causal agents, cofactors, or opportunistic infections or co-infections in patients with various diagnoses [7] [11] [45] [46] [47]. As stated above, various mycoplasmas can be found as normal flora in the genitourinary tract, oral cavity, gut and other sites, but they are not thought to be pathogenic at these superficial sites [7] [45] [46] [47].

The determining factor on whether mycoplasma infections are pathogenic in various diseases and illnesses or simply bystanders could be the requirement that pathogenic mycoplasmas must penetrate into the blood circulation and eventually enter into tissues and cells. This could explain the routine result of finding pathogenic mycoplasmas in the genitourinary tract, oral cavity, gut and occasionally in the blood of asymptomatic subjects. Unless mycoplasmas penetrate into the blood circulation and eventually enter tissues and cells, it may be un- 
likely that they can exert their full pathogenic effects [6] [7] [45] [46] [47].

\subsection{Laboratory Testing for Pathogenic Mycoplasmas}

The clinical detection of Mycoplasma species has been achieved using in vitro culture, serology or molecular detection of DNA or RNA (reviewed in [40]). Although the first two approaches have been used extensively, they have many limitations. For example, the slow and fastidious growth of most Mycoplasma species precludes in vitro culture as a practical, reliable method of detection. Pathogenic mycoplasmas generally require intracellular conditions for growth, and this cannot be easily duplicated in culture. Serological testing is also difficult because of the possibility of suppression of immune responses and the sequestering of pathogenic mycoplasma antigens inside cells and away from the immune system. Thus more recent publications have used molecular techniques, such as various methods of polymerase chain reaction (PCR) for detection of Mycoplasma species [40].

However, there are still some problems with many of these methods due to specimen limitations, availability of clinical samples that contain pathogenic mycoplasmas, rapid sample degradation, the presence of inhibitors or interfering factors and other considerations. Some of the technical limitations have been extensively discussed by Waites et al. [40] and will not be further considered here.

Non-amplified DNA hybridization methods have also been used successfully in a few studies, for example for $M$. fermentans sequences [48]. In general, these test formats suffer from the complex nature of the tests themselves, their reliability and the requirement for sufficient numbers of microorganisms for a positive result.

In studies where both serology and PCR were used there were often differing results, depending on the time of sampling, antibody type (IgM, IgG, IgA, etc.) examined, PCR method used, and other factors [49]. New methods have been developed using, for example, matrix-assisted laser desorption ionization-time of flight mass spectrometry or other techniques, but these are time-consuming, costly and have not been thoroughly evaluated [40]. Thus there remain some questions on whether negative test results using currently and routinely available diagnostic procedures are truly reliable indicators that mycoplasmal infections are not involved.

\subsection{Respiratory Infections}

Pathogenic mycoplasmas have been routinely observed in community-acquired respiratory infections, such as atypical pneumonia [40] [50]. Indeed, $M$. pneumoniae represents one of the more common and potentially dangerous etiological agent found in interstitial pneumonia, and it is often associated with a long-lasting tracheobronchitis in children and adults [50] [51]. Indeed, this infection is often overlooked in adults, even though it is quite commonly found in 
certain communities, such as in the military [52] [53]. In addition to the recognition of $M$. pneumoniae as a possible etiological agent in primary atypical pneumonia, it is also found in other inflammatory and autoimmune diseases, such as various forms of arthritis (to be discussed below).

Along with their ability to act as precipitators, cofactors or progression factors in severe respiratory diseases, pathogenic mycoplasmas have been found to facilitate alterations in local respiratory immunity, such as activation or suppression of pulmonary macrophages or T-cells. In addition, some mycoplasmas have the capacity to alter the structures and functions of host pulmonary cells, such as activation and inflammation of lung epithelium and endothelium, especially by secretion of cytokines, enzymes and other molecules [49] [50] [51] [52].

The pathogeneticity of $M$. pneumoniae is thought to be based, at least initially, on its adhesion to respiratory epithelial cells. Once attached to epithelial cells, its unique gliding motility and the induction of pathological hyper-stimulation of local host cellular response mechanisms appear to be important [19] [21] [35] [40]. During the acute phase of either primary or secondary infections by $M$. pneumoniae cytokines commonly associated with innate resistance and inflammation are expressed [28]. Host responses involving pulmonary macrophages, mast cells, neutrophils, natural killer cells, and T and B cells as well as humoral antibody responses have been extensively studied in pathogenic mycoplasma respiratory infections [27] [35] [40]. Thus the pathogenesis of $M$. pneumoniae lung infections is known to be associated with host responses and elevated expression of certain proinflammatory cytokines. It is also associated with extensive tissue damage and the expression of non-cytokine host factors [19] [21] [40]. In some patients this can result in a fatal course of the infection with multi-system involvement [54]. Tissue and cell damage caused by pathogenic mycoplasma-released enzymes and toxins were briefly discussed above, and several additional mechanisms have been described [39]-[44] [50].

Pathogenic mycoplasmas like $M$. pneumoniae have the capacity to mimic some of the structures of pulmonary host cells, and this could be important in allowing colonization and escape from host pulmonary immune recognition. For example, antigenic similarities between important functional adhesion molecules of $M$. pneumoniae and various host cell surface molecules could be one of the factors responsible for hindering host recognition and response mechanisms and could determine host failure to protect against repeated mycoplasma pulmonary colonizations [40] [50].

In addition to pneumonia, pathogenic mycoplasmas have for some time been implicated in the pathogenesis of chronic asthma [35] [40] [50]. Indeed, allergic sensitization and respiratory pathogens have been known for some time to be important in the inception of asthma [55]. Waites et al. have discussed the evidence for pathogenic mycoplasma infections in chronic asthma and its exacerbations [40]. 


\subsection{Oral Infections}

Various pathogenic mycoplasmas have been implicated in a variety of clinically important oral infections [6] [40]. Indeed, Mycoplasma species infections have been implicated in diseases of the gingival crevices and respiratory tract, and they have been found at high incidence in patients with gingivitis and periodontitis [56]. For example, mycoplasmas were cultured from almost all saliva and plaque samples in children with gingivitis [57]. Although their pathogenesis in oral diseases has not been well studied, various pathogenic mycoplasma species are able to induce cytokine secretion by gingival fibroblasts. Although mycoplasmas have been isolated using throat swabs, sputum and tracheal secretions, they are also routinely found in the oral cavities of normal hosts where they apparently do not cause symptoms. Thus the rather common finding of mycoplasmas, even pathogenic mycoplasmas, in the oral cavities of non-symptomatic subjects may simply reflect their superficial colonization of these sites. Unless accompanied by other pathogenic microorganisms, or if tissue damage occurs that allows entry of the mycoplasmas into surrounding tissues and blood circulation, they may not routinely express their full pathogenic potentials [6] [7].

\subsection{Airway Inflammation}

Pathogenic mycoplasma respiratory tract infections can result in airway inflammation and induction of bronchial hyper-responsiveness (BHR) [58]. The production of $M$. pneumoniae-specific IgE and IgA may play an important role in exacerbation of BHR and asthma. Elevated IgE antibodies specific to M. pneumoniae have been detected in the serum of children with $M$. pneumoniae pneumonia, and in patients with preexisting asthma-BHR increased levels of $M$. pneumoniae specific IgE and IgA occurred after infection (reviewed in [59]). Mycoplasmal infections are also routinely involved in severe asthma-BHR attacks in adults. For example, $M$. pneumoniae was isolatable in $24.7 \%$ of patients with asthma but in only $5.7 \%$ of control subjects, suggesting that this pathogenic mycoplasma plays a role in asthma attacks [60].

Although pathogenic mycoplasma infections are often associated with chronic asthma, the exact role of mycoplasmas in the pathogenesis of asthma remains unclear [59]. Mycoplasmas are likely only one of many agents that can trigger BHR, and other co-infectious or chemical agents may contribute to a complex disease process.

\subsection{Urogenital Infections}

Pathogenic mycoplasmas are commonly found in urogenital infections, such as M. genitalium, M. fermentans, M. hominis, M. pneumoniae and Ureaplasma urealyticum [61]. Importantly, M. hominis and U. urealyticum have been implicated in a wide variety of urogenital diseases, such as pelvic inflammatory disease, infertility, non-gonococcal urethritis (NGU) and other genital infections. Pathogenic mycoplasmas have been isolated from various tissues of patients, 
such as urethra, fetal-placental tissue, cervix, endometrium, vagina, various wounds, and from urine, blood, peritoneal fluid, and amniotic fluid. M. hominis was one of the first mycoplasmas to be isolated from urogenital infections, and this species has been strongly associated with bacterial vaginosis [62]. The sequence of appearance of various pathogenic mycoplasma species in bacterial vaginosis may be a result of pathophysiological alterations of the vaginal ecosystem, and mycoplasmas appear to play an important role in this process. Pathogenic mycoplasmas are but one class of many types of bacterial infections that can be present at various times and in varying amounts in the vaginal ecosystem.

There is good evidence, however, for an etiological role for $U$. urealyticum in acute NGU and its chronic forms in men. This species was found in a majority of male patients with NGU, and sexually transmitted $U$. urealyticum, M. hominis or Chlamydia trachomatis infections have been detected in approximately one-half of 400 young symptomatic females under the age of 30, and a majority of 86 pregnant women with sexually transmitted diseases. Although the incidence rate of the detected microorganisms varied in different reports, infections with pathogenic mycoplasmas are thought to be an important cause or cofactor in many patients with urogenital conditions, such as inflammations, fertility problems and premature deliveries.

Some commonly found pathogenic mycoplasmas are not usually associated with NGUs. For example, $M$. fermentans, $M$. penetrans, and $M$. pirum were not found in urethral swab specimens collected from male patients with or without acute NGU. Although $M$. fermentans was not detected by PCR or culture methods in patients with urethritis or cervicitis, this species was detected by PCR in 4 of 232 amniotic fluid samples tested. The results suggest that in these four cases $M$. fermentans was transferred transplacentally. Histological evidence of chorioamnionitis was present in two of the four patients, a finding that supports the hypothesis that $M$. fermentans may be a possible cause of chorioamnionitis.

\subsection{Infertility and Spontaneous Abortion}

Pathogenic mycoplasmas are known to reduce fertility rates [63]. For example, $U$. urealyticum was found to be involved in a number of patients with fertility problems. This has been related to both women and men with these infections, and successful treatment has been correlated with improvements in fertility. For example, in men $U$. urealyticum infection was found to reduce sperm motility and viability, which are directly related to fertility, and treatment of this infection resulted in improvements in quantity, motility, and appearance of sperm, and importantly, in improvements in fertility [64]. Multiple studies on several species have shown that pathogenic mycoplasma infections are a risk factor for male infertility [65].

The mere presence of pathogenic mycoplasmas on, for example, the vaginal mucosal surfaces of the cervix or vagina is not necessarily an indication of infertility, because $U$. urealyticum and $M$. hominis may occur in $40 \%$ to $80 \%$ of asymptomatic women. However, where inflammatory infections of the upper 
urogenital tract occur and are related to mycoplasmal infections, there was a good correspondence with infertility [64]. Although infections of the lower genital tract are not well correlated with infertility and adverse pregnancy outcomes, pathogenic mycoplasma infections of the upper tract and chorioamnion were strongly associated with adverse pregnancy outcomes [66]. The evidence in experimental animal infections is even clearer. In these cases Koch's postulates have been fulfilled. In addition, a portion of infertile clinical cases of nongonococcal urethritis have been confirmed as caused by pathogenic mycoplasmas [64].

Pathogenic mycoplasmal infections also cause spontaneous abortions and a higher risk of birth complications, such as post-Cesarean delivery endometritis [64]. Pathogenic mycoplasma infections appear to be important in prematurity, pregnancy loss, chorioamnionitis and other complications. These microorganisms can invade the amniotic cavity and cause intense inflammatory reactions in the absence of labor [66].

\subsection{Immunosuppressive Diseases}

One of the most immunosuppressive diseases in humans is caused by the human HIV-1 virus. Various Mycoplasma spp. have been implicated as infectious cofactors along with HIV-1 virus in the pathogenesis of HIV-AIDS [67] [68]. Using relatively insensitive techniques three mycoplasma species have been detected in patients with HIV-1 infections, and the incidence of systemic mycoplasmal infections in HIV-AIDS patients is likely much higher than previously thought. Possible mechanisms that could allow mycoplasmas to influence HIV pathogenesis appear to be the specific and direct activation or suppression of the immune system, the production of superantigens with subsequent alterations in immune responses, and their contribution to the oxidative stress observed in HIV-positive patients [68] [69].

Specific species of mycoplasmas have been isolated from HIV-infected individuals. Mycoplasma fermentans was the first mycoplasma species reported in AIDS patients, and there is evidence that it is an important cofactor in the progression of AIDS [70]. M. fermentans co-infection occurs with HIV-1 infections in approximately one-half of patients with AIDS [71], and lower percentages of other pathogenic mycoplasma species have also been identified [72] [73].

Mycoplasma molecular mimicry may be involved in the pathogenesis of AIDS. Antigen similarities between the surface components of pathogenic mycoplasmas and HIV-1 have led to speculation that they use similar mechanisms for cell entry. Interestingly, the HIV-1 gp120 envelope glycoprotein and M. genitalium adhesin proteins share sequence homology and also have significant similarity with the CD4-binding site of the class II major histocompatibility complex (MHC) proteins. The interactions of pathogenic mycoplasmas with MHC-related antigens on host cells could contribute to a number of possible outcomes, including T-cell dysfunction, T-cell depletion, T-cell shift, B-cell proliferation, hyperglobulinemia and antigen-presenting cell dysfunction. All of 
these have been observed during the development and progression of HIV-AIDS [74].

\subsection{Rheumatic Diseases}

Although the underlying causes of rheumatic diseases, for the most part, remain unknown, these diseases appear to involve, at least in part, infectious agents [75] [76]. Also, the progression of rheumatic diseases may be related to infectious processes. The clinical and pathological similarities between known infectious diseases in animal species and those of some human rheumatic diseases, such as rheumatoid arthritis, have supported microbial etiologies. In fact, there is a long list of microorganisms, including aerobic and anaerobic bacteria, as well as viruses, that have been proposed as important in these illnesses. Among these possible infectious agents are various species of pathogenic mycoplasmas [6] [75].

There is increasing evidence that pathogenic mycoplasmas may promote the progression of rheumatic diseases, such as rheumatoid arthritis (RA) [6] [75]. First, mycoplasmas have been proven to cause arthritis in animals [77]. Second, various pathogenic species of mycoplasmas have been detected in the synovial fluid and blood of RA and other arthritis patients [78] [79]. Although a few reports have not confirmed this, possibly because of the insensitive techniques used for detection, various species of pathogenic mycoplasmas have been localized in the joint tissues of patients with arthritis [59] [78] [80].

Pathogenic mycoplasmas are known to be able to induce immune dysfunction and autoimmune reactions that could be related to the development of arthritis [21] [40] [45] [59]. Thus, mycoplasmal infections could be, in part, involved in the pathogenesis of RA [20] [40] [78]. In animal models of arthritis, $M$. arthritidis-related superantigens were found to compromise T-cells, and they can trigger and exacerbate autoimmune arthritis. These superantigens involve parts of a $\mathrm{T}$-cell receptor that has been proposed to be involved in arthritis [81]. Furthermore, mycoplasmas can release substances, such as oxygen free radicals and chemotactic and aggregating substances that could interact with mononuclear and other cell types.

Importantly, the injection of isolated membranes from $M$. arthritidis resulted in toxicities in animals similar to those found in rheumatic disease [82]. This might be related to correspondence in the antigenic epitopes of chondrocytes and $M$. arthritidis membrane components. Similarly, using immunological methods the presence of trace amounts of pathogenic mycoplasmal antigens or specific antibodies against pathogenic mycoplasma species were found quite often in RA patients [82].

\subsection{Cardiovascular Diseases}

Infections of the cardiovascular system by pathogenic mycoplasmas have been reported recently in patients with different forms of carditis [40] [59]. This has 
also been found in chronic M. pneumoniae infections [59]. Indeed, endocarditis and myocarditis associated with $M$. pneumoniae infections appear to be important causes in the fatal outcomes in M. pneumoniae-infected patients [83]. Direct invasion of $M$. pneumoniae into pericardial tissue appears to be the likely cause of pericarditis, rather than autoimmune phenomena [83].

\subsection{Autoimmune Diseases}

Pathogenic mycoplasmas seem to play an important but not well-understood role in many autoimmune diseases. Several characteristics of mycoplasmas make them attractive as agents that could be responsible for triggering autoimmune responses. First, during their intracellular replication and release from host cells mycoplasmas can capture antigens from the host cell surface and incorporate them into their cell membranes. This can lead to concomitant immune responses against these host antigens and possibly autoimmune reactions. Second, mycoplasmal antigens often mimic host antigens. If immune responses are generated against these mycoplasmal antigens, the result could be cross-reactivity to normal host antigens. Third, mycoplasmas can cause apoptosis of host cells with subsequent release of normal host antigens that could elicit host autoimmune responses.

There is an example of a pathogenic mycoplasma superantigen immunomodulator that can be found during $M$. pneumoniae infections and cause transient autoimmune hemolytic disorders characterized by high titers of autoantibodies, in this case against carbohydrate antigens [84]. The effects of super-antigens on immune systems may be elicited through their binding to the outer portions of MHC structures on antigen-presenting cells and to the non-antigen recognizing structures of the hypervariable regions of T-cell antigen receptors [81]. Such super-antigens can also induce immunological tolerance [81]. When injected into mice, $M$. arthritidis super-antigen causes a chronic arthritis that resembles RA histologically. This mycoplasma species produces a super-antigen (MAM) that in humans preferentially expands T-cells whose antigen receptors (TCR) express the segment Vbeta17. $\mathrm{T}$ cells with this phenotype appear to be increased in frequency in RA synovial effusions. In addition to resembling human RA pathologically, other diseases, such as Kawasaki disease, Sjögren syndrome, lupus erythematosus and multiple sclerosis also show oligoclonal expression of TCR beta specificities on infiltrating T-cells [85].

\subsection{Neurodegenerative and Neurobehavioral Diseases}

Infections have been recently considered to be important in neurodegenerative and neurobehavioral diseases [45] [46] [47] [86]. Infectious bacterial agents, such as Mycoplasma spp., Chlamydia pn., Borrelia spp., among others, can enter the central nervous system (CNS) by direct penetration of the blood-brain-barrier, intraneuronal transfer, or by being carried inside infiltrating mononuclear cells [46] [86]. Once inside the CNS such infections appear to be common features of various neurodegenerative conditions that cause dementia and other brain im- 
pairments [46]. Neurobehavioral disorders overlap with neurodegenerative diseases in their signs and symptoms and can be found in brain disorders of mainly the elderly, such as stroke, dementia, multiple sclerosis and other disorders, as well as disorders of the young, such as autism spectrum disorders, attention deficit disorders and other brain developmental impairments. Both types of conditions are poorly understood and generally poorly addressed clinically [87].

To understand the complexities of neurodegenerative and neurobehavioral disorders there are a variety of considerations, including genetics, immune functions, head trauma, nutritional deficiencies, mitochondrial defects, oxidative stress, environmental toxins, heavy metal and chemical exposures, neurotransmitter abnormalities and chronic viral and bacterial infections [45] [46] [47] [86] [87]. Here we will only consider the potential role of chronic pathogenic mycoplasmal infections in these diseases.

A major adult onset neurodegenerative disease, amyotrophic lateral sclerosis (ALS), is an example of a progressive CNS disease that ultimately results in death, usually by paralysis and respiratory failure due to destruction of upper motor neurons in the cortex and lower motor neurons of the brain stem and spinal cord [88]. Evidence for the presence of particular viruses and intracellular bacteria in the brains of ALS patients has stimulated explorations for various pathogens [45] [46]. In fact, pathogenic mycoplasmal infections were found to be quite common in veterans and civilians with ALS, with $83 \%$ of ALS patients showing positive blood results compared to less than $9 \%$ of controls [89]. Some of these ALS patients also were positive for Borrelia infections. All of the Gulf War veterans with ALS that were tested were mycoplasma-positive, and almost all had $M$. fermentans infections [89]. Many patients with an incomplete diagnosis of ALS were also positive for mycoplasmal infections [46]. A recent study found that $46 \%$ of civilian ALS cases were positive by PCR [90].

Another rather common neurodegenerative disease, multiple sclerosis (MS), also shows evidence of chronic viral and bacterial infections, but in this case mycoplasmal infections were rarely found in brain tissue [91]. A somewhat different result using a different test source was obtained with female MS patients in remission. These patients were found to have higher levels of $M$. pneumoniae antibodies in their serum, suggesting that mycoplasmal infection(s) may be, in fact, related to progression in certain MS patients [92]. A more common finding was the presence of Chlamydia pn. in MS patients [93]. In MS the presence of various viruses, including human retroviruses, has shifted the focus to now look for endogenous viruses [94].

Neurobehavioral disorders, such as autism spectrum disorders (ASD) in children, also show high frequencies of chronic bacterial and viral infections. Several Mycoplasma species, Chlamydia pneumoniae, and human herpes-6 co-infections were found in the blood of a majority of children with ASD [95]. An association has also been found between ASD and Borrelia burgdorferi infections [96]. This has resulted in a proposal for long-term antibiotic therapy for children with ASD and associated conditions [97]. 


\subsection{Fatiguing Illnesses}

The most common fatiguing illness is chronic fatigue syndrome (CFS) or myalgic encephalomyelitis. This is an unexplained, long-term, persistent illness characterized by disabling fatigue plus additional signs and symptoms [98] [99]. Most if not all patients with CFS show evidence of chronic viral and bacterial infections (reviewed in [45] [47]). In fact, the odds ratio for the presence of chronic infections was calculated to be 18.0 ( $\mathrm{p}<0.001)$, suggesting that CFS patients have a very high probability of multiple chronic infections [100]. The most commonly found infections (by PCR of blood monocytes) were various pathogenic species of mycoplasmas [100] [101]. M. pneumoniae was the most common mycoplasma species found, followed by $M$. fermentans, $M$. hominis, and $M$. penetrans [101]. In European CFS patients these infections were also found, but in different frequencies. M. hominis was the most commonly found pathogenic mycoplasma in European CFS patients, suggesting that there are regional differences in the pathogenic mycoplasmal infections found in CFS patients [102]. In CFS patients the number of different chronic infections found in patients may also be important, because patients with multiple infections have a more severe illness course, in terms of the severity of their signs and symptoms [103].

A related fatiguing illness, fibromyalgia (FM) has many of the signs and symptoms of CFS, but its characteristic symptoms are diffuse widespread pain and other symptoms [104]. FM is often diagnosed along with CFS, and these two illnesses generally have overlapping signs and symptoms. However, widespread pain is the most characteristic symptom of FM, and it has been described as spontaneous pain, burning pain, pressure pain, and combinations of these [104]. Infections are a suspected trigger in FM, and various viral and bacterial infections have been found in FM patients (reviewed in [104]). Among the most frequent infections found are various pathogenic species of Mycoplasma [47] [101].

Another fatiguing illness is Gulf War Illness (GWI) [48] [89] [105]. GWI loosely fits the symptom profile of CFS, but depending on the multiple environmental exposures of veterans during this conflict symptoms can vary and include fatigue, pain, cognitive problems, gastrointestinal symptoms and respiratory and skin problems [105] [106]. This group of illnesses is thought to be caused by multiple hits, mainly through chemical and biological exposures. Many if not most GWI cases show evidence of pathogenic mycoplasmal infections (in about one-half of cases), and the majority of these were found to be $M$. fermentans infections [48] [89]. In fact, treating such infections with long-term anti-microbial therapy resulted in recoveries, but not with every patient [48] [105].

\subsection{Other Illnesses and Conditions}

There are a variety of other illnesses and diseases where pathogenic mycoplasmal infections can cause morbidity [45] [46] [47]. For example, Guillain-Barré syn- 
drome, characterized by muscle weakness, pain, numbness, tingling in the arms, face and legs, among other symptoms, is a demyelinating neuropathy often associated with bacterial infections [107]. M. pneumoniae infections are commonly found in over one-half of Guillain-Barré syndrome patients [108]. As discussed above, $M$. pneumoniae infections are common in children, and they can be present as an important co-infection with other bacteria. As an example of this, pathogenic mycoplasma co-infections are often found in infectious illnesses like PANDAS (pediatric autoimmune neuropsychiatric disorders associated with Strepococci) [109]. Another PANDAS-related condition, Tourette's syndrome, has also been related to the involvement of bacterial co-infections, such as Borrelia spp. and Mycoplasma pn. [110] [111].

Infections like pathogenic mycoplasmas have also been found associated with a number of cancers, such as lymphomas [112], oral carcinomas [113], prostate cancers [114] and lung cancers [115]. Mycoplasmal infections can promote malignant transformation in vitro [116] and in vivo [117].

Various systemic illnesses involving different tissues and organs, such as vasculitis, dermatitis, neuritis, hepatitis, sarcoidosis, encephalitis, pancreatitis, hematologic illnesses, among others, can apparently be caused or promoted by pathogenic mycoplasma infections. Matsuda has listed a number of other conditions and illnesses that are linked to mycoplasmal infections (see Figure 1 [118]).

\section{Conventional Treatment of Pathogenic Mycoplasmal Infections}

Pathogenic mycoplasmal infections can occur alone or as co-infections with other microorganisms. Most often they are present with other bacteria, viruses, fungi, etc. in complex multiple infections, as discussed in various sections above. In many cases mycoplasmal infections are not the definitive infection that defines the condition. An example of this is chronic Lyme disease, a complex clinical condition with Borrelia species as the prominent infectious agent but with other bacterial, parasite, and viral components as co-infections [47] [119] [120] [121]. Pathogenic mycoplasmal co-infections are important in such multiple infection diseases, being present in up to $80 \%$ of chronic Lyme diseases cases [120] [122]. These multi-infectious conditions have been called Multiple Systemic Infectious Disease Syndromes (MSIDS) [121], and they present a significant treatment challenge to practitioners due to the number of infections involved, the wide variety of symptoms found, and the difficulty of finding effective treatments for complex clinical conditions [119] [120] [121].

\subsection{Antimicrobial Treatments}

There remains an ongoing controversy whether to treat clinically patients who have mycoplasmal infections. Even with mycoplasmal involvement as possible causes of chronic illnesses, as co-factors or as bystanders causing co-morbid conditions, this controversy has endured [45] [47] [123]. These notions will not 
be considered here, but the most important concept for practitioners and patients is whether recovery from complex chronic illnesses with infectious components can be affected without taking into account the extensive morbidity that can be caused by pathogenic mycoplasmas. Treatment or not of such infections present in many chronic illnesses may be among the most important decisions that practitioners render for their chronically ill patients.

The conventional antimicrobial treatments of pathogenic mycoplasmal infections usually involve systemic therapy with oral antibiotics, but the choice of antibiotic(s) depends to a certain degree on the mycoplasma species being treated. Since mycoplasmas do not have a cell wall, antibiotics that act on cell wall synthesis are ineffective [2] [3] [7] [40] [50] [59] [124] [125]. Instead, mycoplasmas are treated with anti-microbials that attack their metabolism, replication, synthetic machinery or other specific bacterial targets. Since most mycoplasmas and ureaplasmas are generally sensitive to tetracyclines (doxycycline, minocycline, among others), with some notable exceptions, these should be considered for frontline treatment, and quinolones (ciprofloxacin, sparfloxacin, levofloxacin, ofloxacin, among others) [125] [126] [127] [128], as alternative treatment. However, M. pneumoniae and $M$. genitalium strains are especially sensitive to macrolides (azithromycin, clarithromycin, erythromycin, among others), whereas $M$. hominis strains are usually resistant [126] [127] [128]. Ureaplasmas are moderately susceptible to macrolides [127] [128]. M. hominis and Ureaplasma urealyticum are generally more resistant to tetracyclines than other species [129] [130], and M. hominis strains have been observed to be resistant to quinolones [131]. Some discussion of these antimicrobials and their uses in treating pathogenic mycoplasmal infections in chronic illnesses can be found in [132] [133] [134].

Mycoplasmal infections have been treated with intravenous antibiotic therapy, but this is generally done for only a short period of time due to potential long-term toxicities [132]. Treatment of pathogenic mycoplasma infections with oral antibiotics generally involves daily or pulsed treatment, such as every-other-day administration, at the maximum dose recommended for a particular antibiotic [132] [133] [134] [135]. Due to the cyclic nature of mycoplasmal proliferation some organizations recommend every-other-day antibiotic regimens [135].

There are important considerations in determing treatment, such as patient age. For example, some suggest that macrolides be considered first for young children with pathogenic mycoplasma infections due to the potential side effects of tetracyclines and quinolones [136]. However, some adverse effects, such as staining of developing teeth in children under the age of eight with tetracyclines, are not much of a problem with some newer antibiotics, such as doxycycline, and in some cases low-dose administration has been used [137].

Another important consideration is antibiotic resistance, which can occur during treatment [132] [138]. A major problem has been the shifting minimum inhibitory dose concentrations required to treat mycoplasmal infections with 
antibiotics, such as treatment of $M$. genitalium infections with oral tetracyclines [139]. This requires increasing dose levels or shifting to a different antibiotic regimen [132].

In most chronic illness patients pathogenic mycoplasma infections do not respond quickly to anti-microbial therapy, so long-term therapy must be considered [123] [132] [133] [135]. Although acute infections involving Mycoplasma species, such as atypical pneumonia [50] [124], have been treated with short periods of antibiotics, this approach is generally ineffective for chronic infections [45] [46] [47] [48] [121] [123] [132] [133]. A major concern during long-term antibiotic treatment is the possibility of antibiotic resistance [140]. This can occur for a number of reasons that are connected to various genes or resistance determinants that, in turn, are linked to various targets and processes, including those that control the metabolism, activation-inactivation, influx and efflux of drugs and other important activities [140]. In general, this can be avoided, when necessary, by switching to another antibiotic [132].

\subsection{Jarisch-Herxheimer Reactions}

When antibiotics are used to treat pathogenic mycoplasmal infections, Jarisch-Herxheimer reactions (J-H reactions) usually occur [132] [141]. These are observed as temporary increases in the severity of signs and symptoms, and $\mathrm{J}-\mathrm{H}$ reactions generally involve fevers, chills, muscle aches, fatigue, skin rashes, pain and other signs and symptoms related to cytokine release [141]. Although there are some rather simple methods to reduce the severity of some $\mathrm{J}-\mathrm{H}$ reactions [132], their appearance with antimicrobial treatments is thought to be due to the release of mycoplasma particles and fragments and subsequent host response and cytokine release. Strong J-H reactions may suggest the efficacy of treatment, but the lack of strong J-H reactions during anti-microbial treatment is not necessarily an indication of treatment failure.

The signs and symptoms of $\mathrm{J}-\mathrm{H}$ reactions during antibiotic therapy usually revert within days from their initial appearance but can go on for some time [132]. A simple approach to reducing J-H reactions may require reducing temporarily the dose of anti-microbial therapy, or rotating therapy, such as changing to antibiotics that display a completely different mechanism of action. In addition, drugs that decrease cytokine production or release can be effective, such as low-dose naltrexone and Cox-2 inhibitors [121]. The use of integrative treatments to mitigate $\mathrm{J}-\mathrm{H}$ reactions will be discussed in section 6.4 .

\subsection{When to Stop Anti-Microbial Therapy}

Other important considerations during the treatment of pathogenic mycoplasma infections are the overall length of treatment or when to stop therapy and how to deal with interfering microenvironments. Conventional guidelines suggest using only limited treatments for microbial infections, but such limited treatments in many chronic illnesses usually do not resolve the illness or the infection [133] 
[142] [143]. Indeed, pathogenic mycoplasmas are slow-growing, cyclic, fastidious, intracellular microorganisms that appear to be less sensitive to antibiotics in their usual in vivo microenvironments [120] [121] [132].

In many but often less than a majority of patients with pathogenic mycoplasmas the infection can be suppressed by short-term antibiotic treatments of a few weeks, but this usually does not completely resolve the infection, and slow relapse often occurs. Thus the in vitro antimicrobial sensitivities of various mycoplasmas may not be useful in determining the time of treatment regimens in vivo, especially because of differing mycoplasma tissue locations and differences in metaboic states. Importantly, routine anti-microbial treatments may not accurately predict the time required to completely suppress systemic mycoplasmal infections in their natural intracellular microenvironments [143]. In most patients this has required prolonged treatments that have resulted in very slow recoveries, often requiring a year or more of treatment [48] [121] [123] [132] [133].

There are a number of factors in vivo that protect pathogenic mycoplasmas from antimicrobial therapies. For example, microbial biofilms may protect some mycoplasmas from antibiotics, allowing these mycoplasmas to survive in the presence of high drug concentrations, a characteristic that has been termed "recalcitrance" [143]. This will be discussed further in section 6.3. The intracellular locations and microenvironments of pathogenic mycoplasmas present additional membrane barriers for conventional drugs. Also, cells naturally try to detoxify chemicals that enter intracellular compartments. In addition, the presence of "persister tolerant" microorganisms, such as metabolically inactive forms, insures that there will always be some survivors after successful antimicrobial therapy. This is thought to occur, in part, by the dormancy of some microorganisms and diminishing antibiotic targets because of reduced metabolism and proliferation variants, along with selective pressures that can account for unusual antibiotic tolerance in certain survivor microbes [144].

There is also the possibility that host immune responses are essential in surveying survivor mycoplasmas that resist antimicrobial treatments. Variant microorganisms can resist surveillance by alteration or suppression of host responses [5] [6] [7] [19] [21] [144]. These and other possibilities could explain why lengthy treatments of antibiotics are required in most chronically ill patients to achieve complete mycoplasma suppression (without complete eradication) and allow patient recovery [7] [48] [132] [133]. Antibiotic therapy alone has not been successful in suppressing mycoplasmal infections in many patients without other treatment considerations [132] [133]. These will be discussed in Section 6 .

There are some alternative procedures that can increase the in vivo effectiveness of antimicrobial therapies. One method that has been used to increase the effectiveness of antibiotics has been the use of agents that increase the penetrability or the intracellular activities or effectiveness of antibiotics or other drugs. 
For example, the anti-malarial drug Plaquenil (hydroxychloroquine) has been used to alkalize intracellular compartments and improve antimicrobial entry and cytotoxic effects [121] [132] [145].

\subsection{Anti-Inflammatory and Other Treatments}

Inflammation can be a major issue in pathogenic mycoplasma infections, especially when multiple infections are involved [121]. Inflammatory cytokines are produced and released during mycoplasmal infections [28] [33] [35], and the levels of inflammatory cytokines have been correlated to patient morbidity [138]. In patients with severe mycoplasma infections inflammation can be serious, and anti-inflammatory treatments have been recommended [146]. For example, in children with severe $M$. pneumoniae infections corticosteroid treatment was temporally associated with clinical and radiographic improvements, and this anti-inflammatory addition to therapy was considered important in reducing patient morbidity [146].

In pathogenic mycoplasma cases with acute, severe inflammation patients have been treated with steroids or other immunosuppressive drugs with or without intravenous administration of immunoglobulins (IVIG) [134]. In the most refractory cases patients have received plasma exchange along with immunosuppressive drugs, but IVIG and plasma exchange remains a good option [147] [148].

Some antibiotics have immunomodulatory effects themselves. For example, tetracyclines and macrolides show some immunomodulatory effects in patients [149] [150]. This may have some advantage by reducing the inflammation associated with pathogenic mycoplasma infections.

There are a number of other considerations for patients with pathogenic mycoplasmal infections, such as allergies, food sensitivities, functional deficiencies, mitochondrial dysfunction, heavy metal and chemical sensitivities, mold and other biotoxins, endocrine and sleep disorders, nervous system dysfunction, pain and other phenomenon that make recovery difficult [121] [132]. Some of these considerations will be discussed in the next section. They are discussed in more detail elsewhere by Horowitz [151]. For the most part integrative treatment considerations are compatible with conventional therapies, and they are often used in conjunction with conventional therapies. Patients can generally continue their dietary supplements and foods while on antibiotics, but most antibiotics should not be taken at the same time of day as dietary supplements [132].

\section{Diet and Integrative Treatments of Mycoplasmal Infections}

As briefly discussed above, treatment of mycoplasmal infections with anti-microbials, such as long-term antibiotics, without other treatment considerations has, in general, been only marginally effective in achieving stable patient 
recoveries [121] [133] [151]. Because of this, moreover, some patients have been inappropriately diagnosed with psychological problems due to their partial or incomplete recoveries [47]. Although the literature is rife with the appearance of pathogenic mycoplasmal infections in psychiatric disorders [47] [134], the persistence of psychiatric symptoms should not be considered the basis of an inability to recover using conventional anti-microbial treatments. Thus the addition of proper diet and integrative medical management along with conventional anti-microbial treatments should be considered, instead of assuming that patients have psychological reasons for not recovering on conventional antimicrobial therapies [131] [132] [133] [151].

\subsection{General Nutritional Considerations}

There are some basic nutritional or dietary considerations for patients undergoing treatment for pathogenic mycoplasma infections [132] [133] [151] [152] [153]. First, avoidance of high-sugar, yeast-containing and processed foods is essential [132] [153]. Decreasing or eliminating simple or refined sugars, alcohol, acid-forming, high-yeast- and trans-fat-containing foods as well as increasing intake of cruciferous vegetables, fish, soluble fiber foods and whole grains are useful for maintaining healthy digestive and immune systems [151] [152] [153].

Pathogenic mycoplasmas deplete many normal cellular molecules, mainly because they have limited genomes and can't synthesize many of the metabolites that they require for growth and proliferation [1] [5] [7] [15] [17] [153]. Restoring depleted nutrients is an essential part of any mycoplasma treatment program [132] [151] [152] [153]. Thus organizing diets to replace mycoplasma-depleted nutrients is especially important [153]. In the next sections consideration of important vitamins, minerals, lipids, proteins and other nutrients will be discussed.

Since fungal (yeast) overgrowth can be a problem, especially during antibiotic therapy, anti-fungal foods and supplements (grapefruit extract, olive leaf extract, garlic extract, berberine, and oregano oil) can be useful in treating or avoiding fungal infections [151] [152] [153]. Simple dietary advice for fungal or yeast overgrowth includes eliminating or significantly reducing yeast-containing and fermented foods, sugars, and alcoholic beverages [151] [152]. Anti-fungal drugs, such as nystatin and diflucan, can also be useful in controlling fungal/yeast infections [132] [151], but careful monitoring and consideration of possible inflammation should be done to improve outcome [151].

Controlling inflammation during therapy through dietary practice is a simple, practical approach. Recommendations include switching to "alkaline" or "Mediterranean" diets that are low in sugar, dairy, and processed meats and that are high in low-sugar fruits, vegetables, and olive oils [151]. There are also some specific illustrations of particular foods that are helpful. For example, poultry eggs contain a number of bioactive components that can modulate inflammation [154]. There is a suggestion that eating raw eggs can reduce the morbidity of chronic mycoplasmal infections, but this has not been tested in controlled clinical trials. Probiotics are important and will be discussed in another section (6.5). 


\subsection{Vitamins, Minerals and Proteins}

Chronic illness patients, and especially patients with chronic pathogenic mycoplasma infections, should be considered depleted in many essential vitamins and minerals that can be replaced by diet or dietary supplements [132] [151] [152] [153]. For example, we have suggested adding sublingual vitamin B complex (riboflavin, thiamine, niacin, pantothenic acid, pyridoxine, folic acid, biotin, cyanocobalamin, choline), and vitamins $\mathrm{A}, \mathrm{C}$ and $\mathrm{E}$ to routine vitamin use [132] [152]. Other mitochondrial replacement supplements that may be useful include coenzyme Q-10 ( $\left.\mathrm{CoQ}_{10}\right)$ L-carnitine, Alpha-lipoic acid, and glycerolphospholipids (see Section 6) [151] [152] [153] [155].

Important minerals that are often depleted during mycoplasmal infections include zinc, magnesium chromium and selenium. These can be replaced by taking mineral supplements [151] [152] [155].

Other useful supplements containing beta-carotene, bioflavoids, and amino acids, such as L-cyseine, L-tyrosine and L-glutamine. A supplement formulation of specific amino acids, Fatigue Reviva ${ }^{\mathrm{TM}}$, has been developed to support amino acid depletion found in conditions of sub-health, such as chronic infections [157]. Buhner [153] also suggests adding L-arginine, L-tryptophan, L-threonine, and L-serine to this mixture of amino acids. Poultry eggs were mentioned in section 6.1 as an excellent source of proteins and other nutritional components.

\subsection{Modifying Mycoplasma Microenvironments}

Pathogenic mycoplasmas can reside in both extracellular and intracellular microenvironments. In the latter they are adept at modifying their microenvironments to optimize uptake or cellular transport of nutrients. Mycoplasmas can also adjust their enzymatic and other activities, depending on where they are located. To provide microenvironments that are not optimal for mycoplasmas, it is imperative that acidity be controlled at both the extracellular and intracellular levels [151]. This has been done extracellularly with antacids or diet that is not acidic. For intracellular regulation of acidity vitamin $\mathrm{C}$, lemon-lime water, a lemon-olive oil drink or fruits and vegetables that raise intracellular $\mathrm{pH}$ have been used to modulate intracellular environments to more alkaline states [132] [151].

Next, the oxidative states of tissues and cells need to be under control to prevent excess oxidative stress, but not too much control, because many natural functions require some free radical oxidants for metabolic and gene regulation. This can safely be accomplished with dietary use of particular anti-oxidants, and there are some excellent examples of natural anti-oxidants that can be useful. Some are mentioned in section 6.2 and elsewhere [132] [151] [152] [153]. Since normal cellular signaling and metabolism are dependent on the presence of natural cellular oxidants, it is important to not interfere with normal cellular oxidative balance, but at the same time controlling excess oxidative stress [158]. Dietary antioxidants, such as beta-cryptoxanthin found in fruits and vegetables, ap- 
pear to be useful in controlling cellular redox states. This turns out to be important in essentially all types of infections, but it has also been found to be particularly important in cancers, neurodegenerative and other diseases [159].

A very safe and effective method to control oxidative stress and reduce inflammation during mycoplasma treatment is the use of hydrogenized water [160]. Molecular hydrogen reduces oxidative stress and cytotoxic oxygen radicals by a gene regulation mechanism not by direct interactions [161]. Hydrogenized water does not interfere with conventional or integrative therapies against mycoplasmas. It can be easily consumed orally without need to worry about contraindications [160].

As mentioned in Section 5, chronic infections can hide in biofilms and be refractory to anti-microbial treatments. There are several natural biofilm-degrading enzymes that can be useful during anti-microbial treatments, such as nattokinase, lumbrokinase, and serrapeptase [151]. Together with monolauren or glycerol monolaurate, an anti-biofilm agent derived from lauric acid found in coconut and other oils [162], these are useful in disrupting biofilm and potentially improving therapy against a variety of microbial pathogens that hide in biofilms. A natural sweetener, stevia, extracted from the leaves of Stevia rebaudiana plant, has also been shown to be a natural biofilm disrupter [163]. Other natural herbal biofilm disrupters, such as extracts of pomegranate, maple syrup, cinnamon and peppermint, have been used separately or together to inhibit biofilms [151].

Chronic infections also stimulate the release of inflammatory cytokines, as discussed in section 5. Natural cytokine inhibitors have been used to reduce inflammation, such as alpha-lipoic acid (ALA). As mentioned previously, ALA has been used for mitochondrial support [155] [156]. ALA has also been shown to be a good inhibitor of inflammatory cytokines in rheumatoid arthritis patients [164]. Other herbs and vegetables, such as curcumin, broccoli seed extracts, cordyceps, Chinese skullcap, Isatis and Houttuynia extracts, have also been used to reduce specifically inflammation during mycoplasmal infections [151] [153].

Inside cells mycoplasmas compete with mitochondria for metabolites and precursor molecules [153] [155] [156]. In most cells mitochondria supply approximately $90 \%$ of cellular energy needs, so having mycoplasmas competing for precursor molecules and stealing high-energy mitochondrial products can result in reduced mitochondrial function and output. This translates to loss of overall energy that is perceived as fatigue and reduced function [155] [156]. Thus it is important that these depleted components be replaced, such as L-carnitine, ALA, $\mathrm{CoQ}_{10}$, and other components, especially membrane glycerolphospholipids [155] [156] (This will be discussed separately in Section 6.8).

\subsection{Herbal Use to Reduce Jarisch-Herxheimer Reactions}

In Section 5, I discussed the J-H adverse reactions that are often found during treatment of pathogenic mycoplasma infections. Various natural supplements and herbs have been used to minimize J-H reactions. Horowitz [151] has discussed the use of smilix, redroot, and boneset to reduce $\mathrm{J}-\mathrm{H}$ reactions. He has 
also discussed the employment of Stephania root, Andrographis, and polygonum (a form of resveratrol) for J-H reactions [151]. In addition, Cordyceps, Chinese skullcap, Isatis and Houttuynia extracts, and the flavones baicalein and wagonin as well as extracts of Scutellaria baicalensis and Acacia catechu have been utilized by either Horowitz [151] or Buchner [153] to reduce inflammation and decrease J-H reactions.

\subsection{Probiotics and Prebiotics for Gut Health}

It is becoming increasing clear that maintenance of an appropriate balance of gut microbes is essential to gastrointestinal and general health [165] [166]. Probiotics and prebiotics (growth and other factors that support gut microbiome balance) have been used in a variety of clinical conditions to rebalance gut microbe proportions and reduce pathogenic bacterial strains. There are a few examples, such as Clostridium difficile-associated diarrhea, where this has this resulted in significant changes in disease status or morbidity [166]. Thus there has been considerable interest in using probiotics and prebiotics in clinical practice, especially for prevention of antibiotic-associated diarrhea [167].

In pathogenic mycoplasma-infected individuals undergoing antibiotic therapy it is especially important to maintain gut microbial balance, so addition of probiotic/prebiotic supplements would be expected to useful for patients [132] [151] [152]. We generally suggest that supplementation be done at maximal suggested doses of probiotic mixtures 1 - 2 hours after oral antibiotics have been taken to reduce gut microbiome susceptibility to unabsorbed antibiotics [132]. Certain probiotic mixtures can lower inflammation and abdominal symptoms, and these appear to be useful [151]. Addition of fiber to the diet, such as flaxseed, has also been suggested to increase bowel movement in order to remove toxic substances and allergins [132] [151].

The use of oral digestive enzymes to help dissolve biofilm was discussed in section 6.3. Such enzymes have also been used to improve food uptake and maintenance of a healthy gut microbiome.

\subsection{Other Herbals and Natural Remedies}

In Section 5, the use of conventional therapies, for the most part antibiotics, to treat pathogenic mycoplasma infections was discussed. This should remain an important, documented strategy for suppressing mycoplasmas. However, some patients do not tolerate favorably antibiotics, and often discontinue their use at inappropriate times. Also, after antibiotic therapies are discontinued, patients often require some additional anti-microbial tactics to maintain mycoplasmal suppression [132]. Therefore, the use of herbal supplements has been added to mycoplasma treatment strategies during and after antibiotics have been stopped [132] [151] [152] [153]. Although for the most part these herbs and natural remedies have not been tested in controlled clinical trials with mycoplasma-infected patients, their use has become so widespread that they should be 
considered on a patient-to-patient basis.

There are many types of herbal extract mixtures and formulations that have been used in patients with pathogenic mycoplasma infections [153]. These include those that contain, in no particular order, cordeceps (Cordycepsspp.), Chinese skullcap (Scutellaria sinensis), Chinese senega root (Polygala tenufolia), kudzu root (Pueraria lobata), isatis (Isatis indigotica and other species), houttuynia (Houttuynia cordata) olive leaf (Olea europaea), berberine (Berberis spp.), uva ursi (Arctostaphylos uva-ursi), pomegranate (Punica granatum), anogeissus (Anogeissus leiocarpus), tea tree (Melaleuca alternifolia), noni (Morinda citrifolia), among others. Buhner [153] has carefully discussed the available evidence justifying the use of these herbal formulations in patients with mycoplasmal infections. Although some herbal mixtures are available as commercial products, such as Myco+ (by Rain Tree available on Amazon.com), for the most part the anti-mycoplasma herbal mixtures can be found on various websites [132] or must be developed de novo for individual patients [153].

\subsection{Oxidative and Other Therapies}

Pathogenic mycoplasmas can exist in both aerobic and anaerobic environments, but in certain tissues, such as joint synovia with lower oxygen tension, they can be considered as borderline anaerobes [1]. As a borderline anaerobe, they should be susceptible to suppression by high oxygen tension. Thus one approach to mycoplasma therapy has been to increase the overall oxygen content of tissues by hyperbaric oxygen, hydrogen peroxide or ozone. These approaches to mycoplasma therapy appear to be mainly cytostatic not cytotoxic, but they have been used in conjunction with other therapies to treat mycoplasma-infected individuals (discussed in [132]).

Immunotherapy has been suggested for mycoplasmal infections, but there are few examples in the literature. In non-human primates mycoplasmal infections have been prophylactically treated by prior immunization with immunogenic surface components [118] [168]. Humans have also been immunized with mycoplasma ( $M$. pneumoniae) components, and the results have generally been promising [169] [170]. Further efforts will have to be made in this area before effective vaccines are available, including the development of more sensitive and quantitative techniques of measurement of mycoplasmas in cells and body fluids [170].

Immune modulators have been used to boost host immunity. For the most part these have been non-specific modulators [132] [133]. For example, bioactive whey proteins, polysaccharides, mushroom extracts, transfer factors and other natural products have been used in patients with mycoplasmal infections. In general, their clinical effectiveness has not been carefully evaluated, and their effacicy has not been documented in clinical trials.

One problem that can potentially interfere with anti-mycoplasmal therapies is the presence of heavy metals in tissues and organs, which can contribute to in- 
flammation and immune dysfunction [121] [151]. Horowitz has discussed the use of chelation and nutritional supplementation in the removal of heavy metals from patients undergoing treatments for chronic infections [151].

\subsection{Membrane Lipid Replacement}

Membrane Lipid Replacement (MLR) is the critically important oral supplementation of membrane glycerolphospholipids to provide replacement molecules that are damaged or lost during pathogenic mycoplasma infections [171] [172] [173]. Replacement membrane phospholipids are important for a variety of cellular and tissue functions and for general health [172]. Patients with chronic illnesses and infections as well as aged individuals are often deficient in undamaged membrane glycerolphospholipids, because dietary sources usually cannot provide enough undamaged MLR lipids for maintenance of cellular membranes [172] [173].

The use of oral MLR glycerolphospholipids with unsaturated fatty acids (example, NTFactor Lipids) in doses ranging from 3 - 4 g per day has proven to be safe and effective for many clinical conditions, including acute and chronic mycoplasmal infections (reviewed in [172] [174]). MLR results in the actual replacement of damaged membrane phospholipids with undamaged (unoxidized) phospholipids to ensure proper functioning of cellular and intracellular membranes, such as mitochondrial inner membranes essential to cellular energy production.

MLR has also been used to reduce fatigue, pain, gastrointestinal and other symptoms [172] [173] [174], and in mycoplasma-infected and other patients it can restore critical cellular membrane functions [173]. MLR can also help remove hydrophobic neurotoxins, such as mold toxins, that can interfere with cellular response mechanisms and mitochondrial function [171] [172].

\section{Final Comments}

There is now a growing awareness that many chronic illnesses are associated with pathogenic mycoplasma infections that are either responsible (causative) for the illness or more likely acting as cofactors, progression factors and certainly factors which are responsible for aggravating patient morbidity, and in some cases possibly even contributing to fatal outcomes [7] [45] [46] [47]. In addition, pathogenic mycoplasmas routinely occur with other pathogens, often in complex multi-infectious syndromes [121]. Once they have been diagnosed, and that is often difficult with currently available tools, the successful treatment of pathogenic mycoplasmas has been challenging, especially in their chronic forms where the reduced effectiveness of conventional therapies, usually antibiotics, has forced us to consider other treatment options, some of which are discussed in this review.

The present review lists a number of contributing factors for successful suppression of pathogenic mycoplasma infections and extends previous efforts [132] 
[133]. However, each of these and other treatment suggestions is ever changing and often difficult to apply to individual cases in a uniform regimen. General recommendations are to initially apply conventional therapies that employ antibiotics best suited for treatment of specific Mycoplasma species at maximum suggested doses either daily or every other day, unless patients are unable to tolerate antibiotics. In this case, integrative therapies should be considered as frontline therapy. The extended treatments of mycoplasmal infections require patience and the flexibility to change treatment strategies if patients do not slowly show improvements in symptom severities. Various integrative medicines and patient support strategies should also be employed during initial and follow-on therapies as outlined but not limited to this review [121] [151]. As stated here and elsewhere, a major problem is under-treatment, and practitioners will have to decide how long to treat individual patients with mycoplasmal and other infections. This author is also acutely aware of the inability of most treatments to completely eliminate chronic pathogenic mycoplasmas. Thus we have focused on suppression, support and recovery rather than complete eradication of pathogenic mycoplasmas, because the latter may be extremely difficult if not impossible to achieve.

Many of the suggestions presented here do not strictly depend on the properties of the pathogen(s) itself; they are instead focused on modification of host microenvironments. Thus different approaches to the therapy of complex infectious illnesses and syndromes involving pathogenic mycoplasmas should always be considered. For example, the MSIDS multifactorial treatment model proposed by Horowitz [121] identifies and treats overlapping symptoms and their downstream effects rather than focusing on individual infections. This and other approaches to therapy may be necessary to overcome the complex natures of pathogenic mycoplasmas and their treatments, including other co-infections, and the abilities of pathogenic mycoplasmas to persist and cause multiple, overlapping symptoms.

\section{Acknowledgements}

I would like to thank present and former colleagues for their intellectual support, and especially my late spouse, Dr. Nancy Nicolson (1953-2019), who survived lethal mycoplasmal infections and stood by me for so many years. This contribution was supported by internal funds from the Department of Molecular Pathology, The Institute for Molecular Medicine.

\section{Disclosures}

The author is a part-time consultant to Nutritional Therapeutics, Inc., Allergy Research Group, Inc., Naturally plus USA and UNIVA Naturally plus Taiwan.

\section{Conflicts of Interest}

The author has no conflicts of interest to declare regarding this contribution. 


\section{References}

[1] Razin, S, Yogev, D. and Naot, Y. (1998) Molecular Biology and Pathogenicity of Mycoplasmas. Microbiology and Molecular Biology Reviews, 62, 1094-1156. https://mmbr.asm.org/content/62/4/1094

[2] Narita, M. (2016) Classification of Extrapulmonary Manifestations Due to Mycoplasma pnaumoniae Infection on the Basis of Possible Pathogenesis. Frontiers in Microbiology, 7, Article 23. https://doi.org/10.3389/fmicb.2016.00023

[3] Taylor-Robinson, D. and Jensen, J.S. (2011) Mycoplasma genitalium: From Chrysalis to Multicolored Butterfly. Clinical Microbiology Reviews, 24, 498-514. https://cmr.asm.org/content/24/3/498 https://doi.org/10.1128/CMR.00006-11

[4] Atkinson, T.P. (2018) Mollicutes: Mycoplasma pneumoniae. In: Ragab, G., Atkinson, T., Prescott, S. and Matthew, L., Eds., The Microbiome in Rheumatic Diseases and Infection, Springer International Publishing, Berlin, 103-111.

https://doi.org/10.1007/978-3-319-79026-8 10

[5] Baseman, J.B. and Tully, J.G. (1997) Mycoplasmas: Sophisticated, Reemerging, and Burdened by Their Notoriety. Emerging Infectious Diseases, 3, 21-32. https://www.ncbi.nlm.nih.gov/pmc/articles/PMC2627593/pdf/9126441.pdf https://doi.org/10.3201/eid0301.970103

[6] Nicolson, G.L., Nasralla, M.Y., Haier, J., Erwin, R., Nicolson, N.L. and Ngwenya, R. (1999) Mycoplasmal Infections in Chronic Illnesses: Fibromyalgia and Chronic Fatigue Syndromes, Gulf War Illness, HIV-AIDS and Rheumatoid Arthritis. Medical Sentinel, 4, 172-176.

https://haciendapublishing.com/medicalsentinel/mycoplasmal-infections-chronic-il lnesses-fibromyalgia-and-chronic-fatigue-syndromes-

[7] Nicolson, G.L., Nasralla, M.Y. and Nicolson, N.L. (1999) The Pathogenesis and Treatment of Mycoplasmal Infections. Antimicrobial and Infectious Disease Newsletter, 17, 81-87.

http://lymeaware.free.fr/lyme/Publications/The\%20Pathogenesis\%20and\%20Treat ment $\% 20$ of $\% 20$ Mycoplasmal\%20Infections.pdf https://doi.org/10.1016/S1069-417X(00)88885-8

[8] Agnas, B. (1997) Sexual Transmitted Diseases (Mycoplasma homonis, Ureaplasma urealyticum and Chlamydia trachomatis) among Young Females. Orvosi Hetilap (Hungarian Medical Journal), 138, 799-803. https://akademiai.com/doi/pdf/10.1556/650.1997.03.02

[9] Svenstrup, H.F., Fedder, J., Kristoffersen, S.E., Trolle, B., Birkelund, S. and Christiansen, G. (2008) Mycoplasma genitalium, Chlamydia trachomatis and Tubal Factor Infertility-A Prospective Study. Fertility and Sterility, 90, 513-520.

https://www.fertstert.org/article/S0015-0282(07)00107-0/fulltext https://doi.org/10.1016/j.fertnstert.2006.12.056

[10] Murtha, A.P. and Edwards, J.M. (2014) The Role of Mycoplasma and Ureaplasma in Adverse Pregnancy Outcomes. Obstetrics and Gynecology Clinics of North America, 41, 615-627. https://doi.org/10.1016/j.ogc.2014.08.010 https://www.obgyn.theclinics.com/article/S0889-8545(14)00072-2/pdf

[11] Bitnun, A. and Richardson, S.E. (2010) Mycoplasma pneumoniae: Innocent Bystander or a True Cause of Central Nervous System Disease? Current Infectious Disease Report, 12, 282-290.

https://link.springer.com/article/10.1007\%2Fs11908-010-0105-4

https://doi.org/10.1007/s11908-010-0105-4 
[12] Weidenfeld, J., Wohlman, A. and Gallily, R. (1995) Mycoplasma fermentans Activates the Hypothalamo-Pituitary Adrenal Axis in the Rat. NeuroReport, 6, 910-912. https://journals.lww.com/neuroreport/Abstract/1995/04190/Mycoplasma fermenta ns activates the.21.aspx https://doi.org/10.1097/00001756-199504190-00021

[13] Wohlman, A., Gallily, R., Yirmiya, R. and Weidenfeld, J. (1997) Characterization of the Effect of Mycoplasma fermentans on the Hypothalamo-Pituitary-Adrenal Axis. Neuroendocrinology, 66, 221-228. https://doi.org/10.1159/000127241

[14] Fadiel, A., Eichenbaum, K.D., El Semary, N. and Epperson, B. (2007) Mycoplasma Genomics: Tailoring the Genome for Minimal Life Requirements through Reductive Evolution. Frontiers in Bioscience, 12, 2020-2028. https://www.bioscience.org/2007/v12/af/2207/list.htm

[15] Razin, S. (1985) Molecular Biology and Genetics of Mycoplasmas (Mollicutes). Microbiological Reviews, 49, 419-455. https://www.ncbi.nlm.nih.gov/pmc/articles/PMC373046/

[16] Razin, S. (1997) Comparative Genomics of Mycoplasmas. Weiner Klinischer Wochenschrift, 109, 551-556. https://www.ncbi.nlm.nih.gov/pubmed/9286058

[17] Glass, J.I., Assad-Garcia, N., Alperovich, N., Yooseph, S., Lewis, M.R., Maruf, M., Hutchison, C.A., Smith, H.O. and Venter, J.C. (2006) Essential Genes of a Minimal Bacterium. Proceedings of the National Academy of Sciences of the United States of America, 103, 425-430. https://www.pnas.org/content/pnas/103/2/425.full.pdf https://doi.org/10.1073/pnas.0510013103

[18] Reddy, S.P., Rasmussen, W.G. and Baseman, J.B. (1996) Isolation and Characterization of Transposon Tn4001-Generated, Cytadherence-Deficient Transformants of Mycoplasma pneumoniae and Mycoplasma genitalium. FEMS Immunology and Medical Microbiology, 15, 199-211.

https://onlinelibrary.wiley.com/doi/pdf/10.1111/j.1574-695X.1996.tb00086.x https://doi.org/10.1111/j.1574-695X.1996.tb00086.x

[19] Baseman, J.B., Reddy, S.P. and Dallo, S.F. (1996) Interplay between Mycoplasma Surface Proteins, Airway Cells, and the Protean Manifestations of Mycoplasma-Mediated Human Infections. American Journal of Respiratory and Critical Care Medicine, 154, S137-S144.

https://www.atsjournals.org/doi/abs/10.1164/ajrccm/154.4 Pt 2.S137 https://doi.org/10.1164/ajrccm/154.4 Pt 2.S137

[20] Schaeverbeke, T., Vernhes, J.P., Lequen, L., Bannwarth, B., Bebear, C. and Dehais, J. (1997) Mycoplasmas and Arthritides. Reviews in Rheumatology English Education, 64, 120-128. https://www.ncbi.nlm.nih.gov/pubmed/9085447

[21] Rottem, S. (2003) Interaction of Mycoplasmas with Host Cells. Physiological Reviews, 83, 417-432.

https://www.physiology.org/doi/pdf/10.1152/physrev.00030.2002 https://doi.org/10.1152/physrev.00030.2002

[22] Klement, M.L., Öjemyr, L., Tagscherer, K.E., Widmalm, G. and Wieslander, A. (2007) A Processive Lipid Glycosyltransferase in the Small Human Pathogen $\mathrm{My}$ coplasma pneumoniae: Involvement in Host Immune Response. Molecular Microbiology, 65, 1444-1457.

https://onlinelibrary.wiley.com/doi/epdf/10.1111/j.1365-2958.2007.05865.x https://doi.org/10.1111/j.1365-2958.2007.05865.x

[23] Zhang, Q. and Wise, K.S. (1996) Molecular Basis of Size and Antigenic Variation of a Mycoplasma hominis Adhesin Encoded by Divergent vaa Genes. Infection and Immunity, 64, 2737-2744. https://iai.asm.org/content/iai/64/7/2737.full.pdf 
[24] McGowin, C.L. and Totten, P.A. (2017) The Unique Microbiology and Molecular Pathogenesis of Mycoplasma genitalium. Journal of Infectious Diseases, 216, S382S388. https://www.ncbi.nlm.nih.gov/pmc/articles/PMC5853509/ https://doi.org/10.1093/infdis/jix172

[25] Burgos, R., Pich, O.Q., Ferrer-Navorro, M., Baseman, J.B., Querol, E. and Pinol, J. (2006) Mycoplasma genitalium P140 and P110 Cytadhesions Are Reciprocally Stabilized and Required for Cell Adhesion and Terminal-Organelle Development. Journal of Bacteriology, 188, 8627-8637. https://jb.asm.org/content/188/24/8627 https://doi.org/10.1128/]B.00978-06

[26] Svenstrup, H.F., Jensen, J.S., Gevaert, K., Birkelund, S. and Christiansen, G. (2006) Identification and Characterization of Immunogenic Proteins of Mycoplasma genitalium. Clinical and Vaccine Immunology, 13, 913-922.

https://www.ncbi.nlm.nih.gov/pmc/articles/PMC1539121/ https://doi.org/10.1128/CVI.00048-06

[27] Christodoulides, A., Gupta, N., Yacoubian, V., Maithel, N., Parker, J. and Kelesides, T. (2018) The Role of Lipoproteins in Mycoplasma-Mediated Immunomodulation. Frontiers in Microbiology, 9, Article 1682. https://www.frontiersin.org/articles/10.3389/fmicb.2018.01682/full https://doi.org/10.3389/fmicb.2018.01682

[28] Zhang, Y., Mei, S., Zhou, Y., Huang, M., Dong, G. and Chen, Z. (2016) Cytokines as the Good Predictors of Refractory Mycoplasma pneumoniae Pneumonia in School-Aged Children. Scientific Reports, 6, Article No. 37037.

https://www.nature.com/articles/srep37037 https://doi.org/10.1038/srep37037

[29] Mühlradt, P.F., Kiess, M., Meyer, H., Süssmuth, R. and Jung, G. (1997) Insolation, Structure Elucidation, and Synthesis of a Macrophage Stimulatory Lipoprotein from Mycoplasma fermentans Acting at Picomolar Concentration. Journal of Experimental Medicine, 185, 1951-1958.

http://jem.rupress.org/content/185/11/1951/tab-pdf https://doi.org/10.1084/jem.185.11.1951

[30] Mühlradt, P.F., Meyer, H. and Jansen, R. (1996) Identification of S-(2,3-Dihydroxypropyl)Cystein in a Macrophage-Activating Lipopeptide from Mycoplasma fermentans. Biochemistry, 35, 7781-7786.

https://pubs.acs.org/doi/pdf/10.1021/bi9602831

https://doi.org/10.1021/bi9602831

[31] Frisch, M., Gradehandt, G. and Muhlradt, P.F. (1996) Mycoplasma fermentans-Derived Lipid Inhibits Class II Major Histocompatibility Complex Expression without Mediation by Interleukin-6, Interleukin-10, Tumor Necrosis Factor, Transforming Growth Factor-Beta, Type I Interferon, Prostaglandins or Nitric Oxide. European Journal of Immunology, 26, 1050-1057.

https://onlinelibrary.wiley.com/doi/10.1002/eji.1830260514 https://doi.org/10.1002/eji.1830260514

[32] Sasaki, Y., Blanchard, A., Watson, H.L., Garcia, S., Dulioust, A., Montagnier, L. and Gougeon, M.L. (1995) In Vitro Influence of Mycoplasma penetrans on Activation of Peripheral T Lymphocytes from Healthy Donors or Human Immunodeficiency Virus-Infected Individuals. Infection and Immunity, 63, 4277-4283. https://www.ncbi.nlm.nih.gov/pmc/articles/PMC173607/pdf/634277.pdf

[33] Kaufmann, A., Mühlradt, P.F., Gemsa, D. and Sprenger, H. (1999) Induction of Cytokines and Chemokines in Human Monocytes by Mycoplasma fermentans-Derived Lipoprotein MALP-2. Infection and Immunity, 67, 6303-6308. 
https://www.ncbi.nlm.nih.gov/pmc/articles/PMC97033/

[34] Brenner, C., Wroblewski, H., Henaff, M.L., Montagnier, L. and Blanchard, A. (1997) Spiralin, a Mycoplasmal Membrane Protein, Induces T-Cell-Independent B-Cell Blastogenesis and Secretion of Proinflammatory Cytokines. Infection and Immunity, 65, 4322-4329.

https://www.ncbi.nlm.nih.gov/pmc/articles/PMC175619/pdf/654322.pdf

[35] He, J., Liu, M., Ye, Z., Tan, T., Liu, X., You, X., Zeng, Y. and Wu, Y. (2016) Insights into the Pathogenesis of Mycoplasma penumoniae. Molecular Medicine Reports, 14, 4030-4036. https://www.spandidos-publications.com/mmr/14/5/4030 https://doi.org/10.3892/mmr.2016.5765

[36] Bendjennat, M., Blanchard, A., Loutfi, M., Montagnier, L. and Bahraoui, E. (1999) Role of Mycoplasma penetrans Endonuclease P40 as a Potential Pathogenic Determinant. Infection and Immunity, 67, 4456-4462.

https://iai.asm.org/content/67/9/4456

[37] Minion, F.C., Jarvill-Taylor, K.J., Billings, D.E. and Tigges, E. (1993) Membrane-Associated Nuclease Activities in Mycoplasmas. Journal of Bacteriology, 175, 7842-7847. https://www.ncbi.nlm.nih.gov/pmc/articles/PMC206960/ https://doi.org/10.1128/jb.175.24.7842-7847.1993

[38] Saitoh, S., Wada, T., Narita, M., Kohsaka, S., Mizukami, S., Togashi, T. and Kajii, N. (1993) Mycoplasma pneumoniae Infection May Cause Striatal Lesions Leading to Acute Neurologic Dysfunction. Neurology, 43, 2150-2151. https://doi.org/10.1212/WNL.43.10.2150

[39] Rawadi, G., Roman-Roman, S., Castedo, M., Dutilleul, V., Susin, S., Marchetti, P., Geuskens, M. and Kroemer, G. (1996) Effects of Mycoplasma fermentans on the Myelomonocytic Linage. Different Molecular Endities with Cytokine-Inducing and Cytocidal Potential. Journal of Immunology, 156, 670-678. https://www.jimmunol.org/content/156/2/670

[40] Waites, K.B., Xiao, L., Liu, Y., Balish, M.F. and Atkinson, T.P. (2017) Mycoplasma pneumonia from the Respiratory Tract and beyond. Clinical Microbiology Reviews, 30, 747-809. https://doi.org/10.1128/CMR.00114-16

[41] Komada, Y., Zhang, X.L., Zhou, Y.W., Ido, M. and Azuma, E. (1997) Apoptotic Cell Death of Human Lymphoblastoid Cells Induced by Arginine Deaminase. International Journal of Hematology, 65, 129-141. https://doi.org/10.1016/S0925-5710(96)00538-5

[42] Molinos, L., Fernandez, R., Dominguez, M.J., Riesgo, C., Escudero, C. and Martinez, J. (1997) Adenosine Deaminase Activity in the Aetiological Diagnosis of Community-Acquired Pneumonia. Scandinavian Journal of Infectious Disease, 29, 287-290. https://www.ncbi.nlm.nih.gov/pubmed/9255891

https://doi.org/10.3109/00365549709019044

[43] Becker, A., Kannan, T.R., Taylor, A.B., Pakhornova, O.N., Zhang, Y., Somarajan, S.R., Galaleldeen, A., Holloway, S.P., Baseman, J.B. and Hart, P.J. (2015) Structure of CARDS Toxin, a Unique ADP-Ribosylating and Vacuolating Cytotoxin from Mycoplasma pneumoniae. Proceedings of the National Academy of Sciences of the United States of America, 112, 5165-5170. https://doi.org/10.1073/pnas.1420308112

[44] Muir, M.T., Cohn, S.M., Louden, C., Kannan, T.R. and Baseman, J.B. (2011) Novel Toxin Assays Implicate Mycoplasma pneumoniae in Prolonged Ventilator Course and Hypoxemia. Chest, 139, 305-310.

https://journal.chestnet.org/article/S0012-3692(11)60069-X/pdf https://doi.org/10.1378/chest.10-1222 
[45] Nicolson, G.L. (2008) Chronic Infections in Neurodegenerative and Neurobehavioral Diseases. Laboratory Medicine, 39, 291-299.

https://academic.oup.com/labmed/article/39/5/291/2504709 https://doi.org/10.1309/96M3BWYP42L11BFU

[46] Nicolson, G.L. and Haier, J. (2009) Role of Chronic Bacterial and Viral Infections in Neurodegenerative, Neurobehavioral, Psychiatric, Autoimmune and Fatiguing Illnesses: Part 1. British Journal of Medical Practitioners, 2, 20-28.

https://www.bjmp.org/content/role-chronic-bacterial-and-viral-infections-neurode generative-neurobehavioral-psychiatric-au

[47] Nicolson, G.L. and Haier, J. (2010) Role of Chronic Bacterial and Viral Infections in Neurodegenerative, Neurobehavioral, Psychiatric, Autoimmune and Fatiguing Illnesses: Part 2. British Journal of Medical Practitioners, 3, 301-311.

https://www.bjmp.org/content/role-chronic-bacterial-and-viral-infections-neurode generative-neurobehavioural-psychiatric-a

[48] Nicolson, G.L. and Nicolson, N.L. (1996) Diagnosis and Treatment of Mycoplasmal Infections in Persian Gulf War Illness-CFIDS Patients. International Journal of Occupational Medicine, Immunology and Toxicology, 5, 69-78.

http://www.immed.org/GWI\%20Research\%20docs/06.26.12.updates.pdfs.gwi/Nicol son-IJOMIT1996.pdf

[49] Lin, L.-J., Chang, F.-C., Chi, H., Jim, W.-T., Huang, D.T., Kung, Y.-H., Huang, C.-Y., Chiu, N.-C. and Chang, L. (2019) The Diagnostic Value of Serological Studies in Pediatric Patients with Acute Mycoplasma pneumonia Infection. Journal of Microbiology, Immunology and Infection, in press.

https://reader.elsevier.com/reader/sd/pii/S1684118218300756?token=71A32FBE2D 315829BB4DFFC4A7DDDC107BADBCCFF9715DF60C78017A8DCE47F1346A0D A5365AD0088E1FDC1AAD5D8825 https://doi.org/10.1016/j.jmii.2018.09.001

[50] Sauter, P.M., van Rossum, A.M.C. and Vink, C. (2014) Mycoplasma pneumoniae in Children: Carriage, Pathogenesis and Antibiotic Resistance. Current Opinion in Infectious Diseases, 27, 220-227.

https://journals.lww.com/co-infectiousdiseases/Abstract/2014/06000/Mycoplasma pneumoniae in children carriage, $\% 20.3$.aspx https://doi.org/10.1097/QCO.0000000000000063

[51] Jacobs, E., Ehrhardt, I. and Dumke, R. (2015) New Insights in the Outbreak Pattern of Mycoplasma pneumoniae. International Journal of Medical Microbiology, 305, 705-708. https://www.ncbi.nlm.nih.gov/pubmed/26319941 https://doi.org/10.1016/j.ijmm.2015.08.021

[52] Cimolai, N., Wensley, D., Seear, M. and Thomas, E.T. (1995) Mycoplasma pneumoniae as a Cofactor in Severe Respiratory Infections. Clinical Infectious Diseases, 21, 1182-1185.

https://academic.oup.com/cid/article-abstract/21/5/1182/357396? redirectedFrom=f ulltext https://doi.org/10.1093/clinids/21.5.1182

[53] Gray, G.C., Duffy, L.B., Paver, R.J., Putnam, S.D., Reynolds, R.J. and Cassell, G.H. (1997) Mycoplasma pneumoniae: A Frequent Cause of Pneumonia among U.S. Marines in Southern California. Military Medicine, 162, 524-526.

https://academic.oup.com/milmed/article/162/8/524/4831693 https://doi.org/10.1093/milmed/162.8.524

[54] Mishra, R., Cano, E., Venkatram, S. and Diaz-Fuentes, G. (2017) An Interesting Case of Mycoplasma Pneumonia Associated Multisystem Involvement and Diffuse 
Alveolar Hemorrhage. Respiratory Medicine Case Reports, 21, 78-81.

https://www.sciencedirect.com/science/article/pii/S2213007117300692 https://doi.org/10.1016/j.rmcr.2017.03.022

[55] Jackson, D.J., Gern, J.E. and Lemanske Jr., R.F. (2016) The Contributions of Allergic Sensitization and Respiratory Pathogens to Asthma Inception. Clinical Reviews in Allergy and Immunology, 137, 659-665.

https://www.jacionline.org/article/S0091-6749(16)00106-8/pdf

https://doi.org/10.1016/j.jaci.2016.01.002

[56] Holt, R.D., Wilson, M. and Musa, S. (1995) Mycoplasmas in Plaque and Saliva of Children and Their Relationship to Gingivitis. Journal of Periodontology, 66, 97-101. https://aap.onlinelibrary.wiley.com/doi/10.1902/jop.1995.66.2.97 https://doi.org/10.1902/jop.1995.66.2.97

[57] Kwek, H.S., Wilson, M. and Newman, H.N. (1990) Mycoplasma in Relation to Gingivitis and Periodontitis. Journal of Clinical Periodontology, 17, 119-122. https://onlinelibrary.wiley.com/doi/abs/10.1111/j.1600-051X.1990.tb01073.x?sid=nl m\%3Apubmed https://doi.org/10.1111/j.1600-051X.1990.tb01073.x

[58] Borak, J. and Lefkowitz, R.Y. (2016) Bronchial Hyperresponsiveness. Occupational Medicine, 66, 95-105. https://academic.oup.com/occmed/article/66/2/95/2750597 https://doi.org/10.1093/occmed/kqv158

[59] Parrott, G.L., Kinjo, T. and Fujita, J. (2016) A Compendium for Mycoplasma pneumoniae. Frontiers in Microbiology, 7, Article 513. https://www.ncbi.nlm.nih.gov/pmc/articles/PMC4828434/pdf/fmicb-07-00513.pdf https://doi.org/10.3389/fmicb.2016.00513

[60] Seggev, J.S., Sedmak, G.V. and Kurup, V. (1996) Isotype-Specific Antibody Responses to Acute Mycoplasma pneumoniae Infection. Annals of Allergy, Asthma and Immunology, 77, 67-73.

https://www.annallergy.org/article/S1081-1206(10)63482-5/pdf https://doi.org/10.1016/S1081-1206(10)63482-5

[61] Combaz-Söhnchen, N. and Kuhn, A. (2017) A Systematic Review of Mycoplasma and Ureaplasma in Urogynaecology. Geburtschilfe und Frauenheilkunde, 77, 1299-1303. https://www.ncbi.nlm.nih.gov/pmc/articles/PMC5734936/

[62] Mardh, P.A., Elshibly, S., Kallings, I. and Hellberg, D. (1997) Vaginal Flora Changes Associated with Mycoplasma hominis. American Journal of Obstretrics and Gynecology, 176, 173-178. https://www.ajog.org/article/S0002-9378(97)80031-2/fulltext https://doi.org/10.1016/S0002-9378(97)80031-2

[63] Al-Farraj, D.A. and Moubayed, N.M. (2019) The Association between Sociodemographic, Hormonal, Tubo-Ovanian Factors and Bacterial Count in Chlamydia and Mycoplasma Infections with Infertility. Saudi Journal of Biological Sciences, 26, 20-23. https://www.sciencedirect.com/science/article/pii/S1319562X16301632 https://doi.org/10.1016/j.sjbs.2016.11.006

[64] Waites, K.B., Katz, B. and Schelonka, R.L. (2005) Mycoplasmas and Ureaplasmas as Neonatal Pathogens. Clinical Microbiology Reviews, 18, 757-789.

https://cmr.asm.org/content/18/4/757 https://doi.org/10.1128/CMR.18.4.757-789.2005

[65] Schuppe, H.C., Pilatz, A., Hossain, H., Diemer, T., Wagenlehner, F. and Weidner, W. (2017) Urogenital Infection as a Risk Factor for Male Infertility. Deutsches Ärteblatt International, 114, 339-346.

https://www.aerzteblatt.de/int/archive/article/188504 
https://doi.org/10.3238/arztebl.2017.0339

[66] Cassell, G.H., Waites, K.B., Watson, H.L., Crouse, D.T. and Harasawa, R. (1993) Ureaplasma urealyticum Intraurerine Infection: Role in Prematurity and Diseases in Newborns. Clinical Microbiology Reviews, 6, 69-87.

https://cmr.asm.org/content/cmr/6/1/69.full.pdf https://doi.org/10.1128/CMR.6.1.69

[67] Lemaitre, M., Henin, Y., Destouesse, F., Ferrieux, C., Montagnier, A. and Blanchard, A. (1992) Role of Mycoplasmas in the Cytopathic Effect Induced by Human Immunodeficiency Virus Type 1 in Infected Cell Lines. Infection and Immunity, 60, 742-748. https://www.ncbi.nlm.nih.gov/pmc/articles/PMC257548/pdf/iai00027-0034.pdf

[68] Ainsworth, J.G., Katseni, V., Hourshid, S., Ball, S., Cattell, V. and Taylor-Robinson, D. (1994) Mycoplasma fermentans and HIV-Associated Nephropathy. Journal of Infection, 29, 323-326.

https://www.journalofinfection.com/article/S0163-4453(94)91289-0/fulltext https://doi.org/10.1016/S0163-4453(94)91289-0

[69] Blanchard, A. (1997) Mycoplasmas and HIV Infection, a Possible Interaction through Immune Activation. Wien Klinische Wochenschrift, 109, 590-593. https://www.ncbi.nlm.nih.gov/pubmed/9286065

[70] Montagnier, L. and Blanchard, A. (1993) Mycoplasmas as Cofactors in Infection Due to the Immunodeficiency Virus. Clinical Infectious Disease, 17, S309-S315. https://www.jstor.org/stable/4457254?seq=1-\%20page scan tab contents\#page sca n tab contents

[71] Li, J.-L., Matsuda, K., Takagi, M. and Yamamoto, N. (1997) Detection of Antibodies against Phosphocholine-Containing Aminoglycoglycerolipid Specific to Mycoplasma fermentans in HIV-1 Infected Individuals. Journal of Immunological Methods, 208, 103-113.

https://www.sciencedirect.com/science/article/pii/S002217599700135X https://doi.org/10.1016/S0022-1759(97)00135-X

[72] Kocacic, R., Launay, V., Tuppin, P., Lafeuillade, A., Feuillie, V., Montagnier, L. and Grau, O. (1996) Search for the Presence of Six Mycoplasma Species in Peripheral Blood Mononuclear Cells of Subjects Seropositive and Seronegative for Human Immunodeficiency Virus. Journal of Clinical Microbiology, 34, 1808-1810. https://jcm.asm.org/content/34/7/1808

[73] Sloot, N., Hollandt, H., Gatermann, S. and Dalhoff, K. (1996) Detection of Mycoplasma sp. in Bronchoalveolar Lavage of AIDS Patients with Pulmonary Infiltrates. Zentralblatt für Bakeriologie, 284, 75-79.

https://www.sciencedirect.com/science/article/abs/pii/S0934884096801563 https://doi.org/10.1016/S0934-8840(96)80156-3

[74] Bisset, L.R. (1994) Molecular Mimicry in the Pathogenesis of AIDS: The HIV/ MHC/Mycoplasma Triangle. Medical Hypothesis, 43, 388-396.

https://www.sciencedirect.com/science/article/abs/pii/0306987794900140 https://doi.org/10.1016/0306-9877(94)90014-0

[75] Jefferies, W.M. (1998) The Etiology of Rheumatoid Arthritis. Medical Hypotheses, 51, 111-114.

https://www.sciencedirect.com/science/article/abs/pii/S0306987798901037 https://doi.org/10.1016/S0306-9877(98)90103-7

[76] Ford, D. (1991) The Microbial Causes of Rheumatoid Arthritis. Journal of Rheumatology, 18, 1441-1442. 
[77] Rivera, A., Yáñez, A., León-Tello, G., Gil, C., Barba, E. and Cedillo, L. (2002) Experimental Arthritis Induced by a Clinical Mycoplasma fermentans Isolate. BMC Musculoskeletal Disorders, 3, Article No. 15.

https://bmcmusculoskeletdisord.biomedcentral.com/articles/10.1186/1471-2474-3-1 $\underline{5}$

https://doi.org/10.1186/1471-2474-3-15

[78] Schaeverbeke, T., Renaudin, H., Clerc, M., Lequen, L., Vernhes, J.P., De Barbeyrac, B., Bannwarth, B., Bébéar, C. and Dehais, J. (1997) Systemic Detection of Mycoplasmas by Culture and Polymerase Chain Reaction (PCR) Procedures in 209 Synovial Fluid Samples. British Journal of Rheumatology, 36, 310-314.

https://academic.oup.com/rheumatology/article/36/3/310/1782740 https://doi.org/10.1093/rheumatology/36.3.310

[79] Haier, J., Nasralla, M., Franco, A.R. and Nicolson, G.L. (1999) Detection of Mycoplasmal Infections in Blood of Patients with Rheumatoid Arthritis. Rheumatology, 38, 504-509. https://academic.oup.com/rheumatology/article/38/6/504/1783454 https://doi.org/10.1093/rheumatology/38.6.504

[80] Furr, P.M., Taylor-Robinson, D. and Webster, A.D. (1994) Mycoplasmas and Ureaplasmas in Patients with Hypogammaglobulinaemia and Their Role in Arthritis: Microbiological Observations over Twenty Years. Annuals of Rheumatic Diseases, 53, 183-187. https://ard.bmj.com/content/53/3/183 https://doi.org/10.1136/ard.53.3.183

[81] Cole, B.C. and Griffith, M.M. (1993) Triggering and Exacerbation of Autoimmune Arthritis by the Mycoplasma arthritidis Superantigen MAM. Arthritis and Rheumatism, 36, 994-1002. https://onlinelibrary.wiley.com/doi/10.1002/art.1780360717 https://doi.org/10.1002/art.1780360717

[82] Kirchhoff, H., Binder, A., Runge, M., Meier, B., Jacobs, R. and Busche, K. (1989) Pathogenic Mechanisms in the Mycoplasma arthritidis Polyarthritis of Rats. Rheumatology International, 9, 193-196. https://link.springer.com/article/10.1007/BF00271879 https://doi.org/10.1007/BF00271879

[83] Narita, M. (2010) Pathogenesis of Extrapulmonary Manifestations of Mycoplasma pneumoniae Infection with Special Reference to Pneumonia. Journal of Infection and Chemotherapy, 16, 162-169.

https://www.sciencedirect.com/science/article/abs/pii/S1341321X10705973 https://doi.org/10.1007/s10156-010-0044-X

[84] Feizi, T. and Loveless, R.W. (1996) Carbohydrate Recognition by Mycoplasma pneumoniae and Pathologic Consequences. American Journal of Respiratory and Critical Care Medicine, 154, S133-S136. https://www.atsjournals.org/doi/pdf/10.1164/ajrccm/154.4 Pt 2.S133 https://doi.org/10.1164/ajrccm/154.4 Pt 2.S133

[85] Kaneoka, H. and Naito, S. (1997) Superantigens and Autoimmune Diseases. Nippon Rinsho. Japanese Journal of Clinical Medicine, 55, 1363-1369. https://europepmc.org/abstract/med/9200919

[86] Mattson, M.P. (2004) Infectious Agents and Age-Related Neurodegenerative Disorders. Ageing Research Reviews, 3, 105-120.

https://www.sciencedirect.com/science/article/pii/S1568163703000394 https://doi.org/10.1016/j.arr.2003.08.005

[87] Zasler, N.D., Martelli, M.F. and Jacobs, H.E. (2013) Neurobehavioral Disorders. Handbook of Clinical Neurology, 110, 377-388. 
https://www.ncbi.nlm.nih.gov/pubmed/23312657

https://doi.org/10.1016/B978-0-444-52901-5.00032-0

[88] Walling, A.D. (1999) Amyotrophic Lateral Sclerosis: Lou Gehrig's Disease. American Family Physician, 59, 1489-1496. https://www.aafp.org/afp/1999/0315/p1489.html

[89] Nicolson, G.L., Nasralla, M., Haier, J. and Promfret, J. (2002) High Frequency of Systemic Mycoplasmal Infections in Gulf War Veterans and Civilians with Amyotrophic Lateral Sclerosis (ALS). Journal of Clinical Neurosciences, 9, 525-529. https://www.sciencedirect.com/science/article/abs/pii/S0967586801910756 https://doi.org/10.1054/jocn.2001.1075

[90] Gil, C., González, A.A.S., León, I.S., Rivera, A., Olea, R.S. and Cedillo, L. (2014) Detection of Mycoplasmas in Patients with Amyotrophic Lateral Sclerosis. Advances in Microbiology, 4, 712-719.

http://www.scirp.org/journal/paperinformation.aspx?paperid $=49483$ https://doi.org/10.4236/aim.2014.411077

[91] Libbey, J.E., Cusick, M.F. and Fujinami, R.S. (2013) Role of Pathogens in Multiple Sclerosis. International Review of Immunology, 33, 266-283.

https://www.ncbi.nlm.nih.gov/pmc/articles/PMC4369909/pdf/nihms672154.pdf https://doi.org/10.3109/08830185.2013.823422

[92] Bahar, M., Ashtari, F., Aghaei, M., Akbari, M., Salari, M. and Ghalamkari, S. (2012) Mycoplasma pneumoniae Seropositvity in Iranian Patients with Relapsing-Remitting Multiple Sclerosis: A Randomized Case-Control Study. Journal of Pakistan Medical Association, 62, S6-S8. https://www.ncbi.nlm.nih.gov/pubmed/?term=22768448

[93] Sriram, S., Mitchell, W. and Stratton, C. (1998) Multiple Sclerosis Associated with Chlamydia pneumoniae Infection of the CNS. Neurology, 50, 571-572.

https://n.neurology.org/content/50/2/571 https://doi.org/10.1212/WNL.50.2.571

[94] Tselis, A. (2011) Evidence for Viral Etiology of Multiple Sclerosis. Seminars in Neurology, 31, 307-316.

https://www.thieme-connect.com/products/ejournals/abstract/10.1055/s-0031-1287 $\underline{656}$

https://doi.org/10.1055/s-0031-1287656

[95] Nicolson, G.L., Gan, R., Nicolson, N.L. and Haier, J. (2007) Evidence for Mycoplasma spp., Chlamydia pneumoniae, and Human Herpes Virus-6 in the Blood of Patients with Autistic Spectrum Disorders. Journal of Neuroscience Research, 85, 1143-1148. https://onlinelibrary.wiley.com/doi/abs/10.1002/jnr.21203 https://doi.org/10.1002/jnr.21203

[96] Bransfield, R.C., Wulfman, J.S., Harvey, W.T. and Usman, A.I. (2008) The Association between Tick-Borne Infections, Lyme Borreliosis and Autism Spectrum Disorders. Medical Hypotheses, 70, 967-974.

https://www.sciencedirect.com/science/article/abs/pii/S0306987707005786?via=ihu $\underline{b}$

https://doi.org/10.1016/j.mehy.2007.09.006

[97] Kuhn, M., Grave, S., Bransfield, R. and Harris, S. (2012) Long Term Antibiotic Therapy May Be an Effective Treatment for Children Co-Morbid with Lyme Disease and Autism Spectrum Disorder. Medical Hypotheses, 78, 606-615. https://www.sciencedirect.com/science/article/abs/pii/S0306987712000485 https://doi.org/10.1016/j.mehy.2012.01.037

[98] Fukuda, K., Strauss, S.E., Hickie, I., Sharpe, M.C., Dobbins, J.G. and Komaroff, A. 
(1994) The Chronic Fatigue Syndrome: A Comprehensive Approach to Its Definition and Study. Annals of Internal Medicine, 121, 953-959.

https://annals.org/aim/article-abstract/708271/chronic-fatigue-syndrome-comprehe nsive-approach-its-definition-study https://doi.org/10.7326/0003-4819-121-12-199412150-00009

[99] Carruthers, B.M., Jain, A.K., De Meirleir, K.L., Peterson, D.L., Klimas, N.G. and Lerner, A.M. (2003) Malgic Encephalomyelitis/Chronic Fatigue Syndrome. Clinical Working Case Definition, Diagnostic and Treatment Protocols. Journal of Chronic Fatigue Syndrome, 11, 7-115.

https://www.tandfonline.com/doi/abs/10.1300/J092v11n01 02

https://doi.org/10.1300/J092v11n01 02

[100] Nicolson, G.L., Nasralla, M., De Meirleir, K., Gan, R. and Haier, J. (2003) Evidence for Bacterial (Mycoplasma, Chlamydia) and Viral (HHV-6) Co-Infections in Chronic Fatigue Syndrome Patients. Journal of Chronic Fatigue Syndrome, 11, 7-19. https://www.tandfonline.com/doi/abs/10.1300/J092v11n02 02 https://doi.org/10.1300/J092v11n02 02

[101] Nasralla, M., Haier, J. and Nicolson, G.L. (1999) Multiple Mycoplasmal Infections Detected in Blood of Patients with Chronic Fatigue Syndrome and/or Fibromyalgia. European Journal of Microbiology and Infectious Diseases, 18, 859-865. https://link.springer.com/article/10.1007/s100960050420 https://doi.org/10.1007/s100960050420

[102] Nijs, J., Nicolson, G.L., De Becker, P., Coomans, D. and De Meirleir, K. (2006) High Prevalence of Mycoplasma Infections among European Chronic Fatigue Syndrome Patients. Examination of Found Mycoplasma Species in Blood of Chronic Fatigue Syndrome Patients. FEMS Immunology and Medical Microbiology, 34, 209-214. https://onlinelibrary.wiley.com/doi/10.1111/j.1574-695X.2002.tb00626.x https://doi.org/10.1111/j.1574-695X.2002.tb00626.X

[103] Nicolson, G.L., Gan, R. and Haier, J. (2003) Multiple Co-Infections (Mycoplasma, Chlamydia, Human Herpes Virus-6) in Blood of Chronic Fatigue Syndrome Patients: Association with Signs and Symptoms. Acta Pathologica Microbiologica Immunologica Scandanavia (APMIS), 111, 557-566.

https://onlinelibrary.wiley.com/doi/10.1034/j.1600-0463.2003.1110504.x https://doi.org/10.1034/j.1600-0463.2003.1110504.x

[104] Breeding, P.C., Russell, N.C. and Nicolson, G.L. (2012) Integrative Model of Chronically Activated Immune-Hormonal Pathways Important in the Generation of Fibromyalgia. British Journal of Medical Practitioners, 5, a524.

https://www.bjmp.org/content/integrative-model-chronically-activated-immune-ho rmonal-pathways-important-generation-fibrom

[105] Nicolson, G.L., Nicolson, N.L., Berns, P., Nasralla, M.Y., Haier, J. and Nass, M. (2003) Gulf War Illnesses: Chemical, Biological and Radiological Exposures Resulting in Chronic Fatiguing Illnesses Can Be Identified and Treated. Journal of Chronic Fatigue Syndrome, 11, 135-154.

https://www.tandfonline.com/doi/abs/10.1300/J092v11n01 04 https://doi.org/10.1300/J092v11n01 04

[106] Janulewicz, P., Krengel, M., Quinn, E., Heeren, T., Toomey, R., Killiany, R., Zundel, C., Ajama, J., O’Callaghan, J., Steele, L., Klimas, N. and Sullivan, K. (2018) The Multiple Hit Hypothesis for Gulf War Illness: Self-Reported Chemical/Biological Weapons Exposure and Mild Traumatic Brain Injury. Brain Sciences, 8, Article 198. https://www.mdpi.com/2076-3425/8/11/198

https://doi.org/10.3390/brainsci8110198 
[107] Bach, J.F. (2005) Infections and Autoimmune Diseases. Journal of Autoimmunity, 25, 74-80. https://www.sciencedirect.com/science/article/pii/S0896841105001320 https://doi.org/10.1016/j.jaut.2005.09.024

[108] Gorthi, S.P., Kapoor, L., Chaudhry, R., Sharma, N., Perez-Perez, G.I., Panigrahi, P. and Behari, M. (2006) Guillain-Barré Syndrome: Association with Campylobacter jujuniand, Mycoplasma pneumoniae Infections in India. National Medicine Journal India, 19, 137-139.

http://archive.nmji.in/archives/Volume 193 May June2006/short report/Guillain Barre syndrome.htm

[109] Shulman, S.T. and Stanford, T. (2009) Pediatric Autoimmune Neuropsychiatric Disorders Associated with Streptococci (PANDAS): Update. Current Opinion in Pediatrics, 21, 127-130.

https://journals.lww.com/co-pediatrics/Abstract/2009/02000/Pediatric autoimmun e neuropsychiatric disorders.18.aspx https://doi.org/10.1097/MOP.0b013e32831db2c4

[110] Müller, N., Riedel, M., Blendinger, C., Oberle, K., Jacobs, E. and Abele-Horn, M. (2004) Mycoplasma pneumoniae Infection and Tourette's Syndrome. Psychiatry Research, 129, 119-125.

https://www.sciencedirect.com/science/article/abs/pii/S0165178104002082 https://doi.org/10.1016/j.psychres.2004.04.009

[111] Krause, D.L. and Müller, N. (2012) The Relationship between Tourette's Syndrome and Infections. Open Neurology Journal, 6, 124-128.

https://www.ncbi.nlm.nih.gov/pmc/articles/PMC3514747/

https://doi.org/10.2174/1874205X01206010124

[112] Ainsworth, J.G.E., Esterbrook, P.J., Clarke, J., Gilroy, C.B. and Taylor-Robinson, D. (2001) An Association of Disseminated Mycoplasma fermentans in HIV-1 Positive Patients with Non-Hodgkin's Lymphoma. International Journal of STD and AIDS, 12, 499-504. https://journals.sagepub.com/doi/abs/10.1258/0956462011923589 https://doi.org/10.1258/0956462011923589

[113] Henrich, B., Rumming, M., Sczyrba, A., Velleuer, E., Dietrich, R., Gerlach, W., Gombert, M., Rahn, S., Stoye, J., Borkhardt, A. and Fischer U. (2014) Mycoplasma salivarium as a Dominant Colonizer of Fanconi Anaemia Associated Oral Carcinoma. PLOS ONE, 9, e92297.

https://www.ncbi.nlm.nih.gov/pmc/articles/PMC3958540/ https://doi.org/10.1371/journal.pone.0092297

[114] Barykova, Y.A., Logunov, D.Y., Shmarov, M.M., Vinarov, A.Z., Fiev, D.N., Vinarova, N.A., Rakovskaya, I.V., et al. (2011) Association of Mycoplasma hominis Infection with Prostate Cancer. Oncotargets, 2, 289-297.

https://www.ncbi.nlm.nih.gov/pmc/articles/PMC3248169/pdf/oncotarget-02-289.pd $\underline{\mathrm{f}}$

https://doi.org/10.18632/oncotarget.256

[115] Jiang, S., Zhang, S., Langenfeld, J., Lo, S.-C. and Rogers, M.B. (2008) Mycoplasma Infection Transforms Normal Lung Cells and Induces Bone Morphogenetic Protein 2 Expression by Post-Transcriptional Mechanisms. Journal of Cellular Biochemistry, 104, 580-594. https://onlinelibrary.wiley.com/doi/abs/10.1002/jcb.21647 https://doi.org/10.1002/jcb.21647

[116] Zhang, S., Tsai, S. and Lo, S.-C. (2006) Alteration of Gene Expression Profiles during Mycoplasma-Induced Malignant Cell Transformation. BMC Cancer, 6, Article No. 116.

https://www.ncbi.nlm.nih.gov/pmc/articles/PMC1559712/pdf/1471-2407-6-116.pdf 
https://doi.org/10.1186/1471-2407-6-116

[117] Zella, D., Curreli, S., Benedetti, F., Krishnan, S., Cocchi, F., Latinovic, O.S., Denaro, F., Romerio, F., et al. (2018) Mycoplasma Promotes Malignant Transformation in Vivo, and Its DnaK, a Bacterial Chaperone Protein, Has Broad Oncogenic Properties. Proceedings of the National Academy of Sciences of the United States of America, 115, E12005-E12014. https://www.pnas.org/content/115/51/E12005 https://doi.org/10.1073/pnas.1815660115

[118] Matsuda, K. (2015) A Novel Therapeutic Strategy for Mycoplasma Infectious Disease. Personalized Medicine Universe, 4, 32-39.

https://www.sciencedirect.com/science/article/abs/pii/S2186495015000164?via=ihu $\underline{\mathrm{b}}$ https://doi.org/10.1016/j.pmu.2015.04.005

[119] Cameron, D.J., Johnson, L.B. and Maloney, E.L. (2014) Evidence Assessments and Guideline Recommendations in Lyme Disease: The Clinical Management of Known Tick Bites, Erythema Migrans Rashes and Persistent Disease. Expert Reviews of Anti-Infective Therapy, 12, 1103-1135.

https://www.ncbi.nlm.nih.gov/pmc/articles/PMC4196523/pdf/ERZ-12-1103.pdf https://doi.org/10.1586/14787210.2014.940900

[120] Horowitz, R.I. and Freeman, P.R. (2019) Precision Medicine: Retrospective Chart Review and Data Analysis of 200 Patients on Dapsone Combination Therapy for Chronic Lyme Disease/Post-Treatment Lyme Disease Syndrome: Part 1. International Journal of General Medicine, 12, 101-119. https://www.ncbi.nlm.nih.gov/pmc/articles/PMC6388746/pdf/ijgm-12-101.pdf https://doi.org/10.2147/IJGM.S193608

[121] Horowitz, R.I. and Freeman, P.R. (2018) Precision Medicine: The Role of MSIDS Model in Defining, Diagnosing and Treating Chronic Lyme Disease/Post Treatment Lyme Disease Syndrome and Other Chronic Illnesses: Part 2. Healthcare (Basel), 6, Article 129.

https://www.ncbi.nlm.nih.gov/pmc/articles/PMC6316761/pdf/healthcare-06-00129. pdf https://doi.org/10.3390/healthcare6040129

[122] Nicolson, G.L., Nicolson, N.L. and Haier, J. (2007) Chronic Fatigue Syndrome Patients Subsequently Diagnosed with Lyme Disease Borrelia burgdorferi: Evidence for Mycoplasma Species Co-Infections. Journal of Chronic Fatigue Syndrome, 14, 5-17. https://www.tandfonline.com/doi/abs/10.3109/10573320802091809 https://doi.org/10.1080/10573320802091809

[123] Nicolson, G.L. (2017) Mycoplasma and Other Intracellular Bacterial Infections in Rheumatic Diseases: Comorbid Condition or Cause? Open Journal of Tropical Medicine, 1, 016-017. https://www.peertechz.com/articles/OJTM-1-103.php https://doi.org/10.17352/ojtm.000003

[124] Biondi, E., McCulloh, R., Alverson, B., Klein, A., Dixon, A. and Ralston, S. (2014) Treatment of Mycoplasma pneumoniae: A Systematic Review. Pediatrics, 133, 1081-1090. https://pediatrics.aappublications.org/content/133/6/1081.short https://doi.org/10.1542/peds.2013-3729

[125] Kenny, G.E. and Cartwright, F.D. (2001) Susceptibilities of Mycoplasma hominis, M. pneumoniae, and Ureaplasma urealyticum to GAR-936, Dalfopristin, Dirithromycin, Evernimicin, Gatifloxacin, Linezolid, Moxifloxacin, Quinupristin-Dalfopristin, and Telithromycin Compared to Their Susceptibilities to Reference Macrolides, Tetracyclines, and Quinolones. Antimicrobial Agents and Chemotherapy, 45, 26042608. https://aac.asm.org/content/45/9/2604 
https://doi.org/10.1128/AAC.45.9.2604-2608.2001

[126] Arai, S., Gohara, Y., Kuwano, K. and Kawashima, T. (1992) Antimycoplasmal Activities of New Quinolones, Tetracyclines and Macrolides against Mycoplasma pneumoniae. Antimicrobial Agents and Chemotherapy, 36, 1322-1324.

https://aac.asm.org/content/36/6/1322

https://doi.org/10.1128/AAC.36.6.1322

[127] Hannan, P.C.T. (1998) Comparative Susceptibilities of Various AIDS-Associated and Human Genital Tract Mycoplasmas and Strains of Mycoplasma pneumoniae to 10 Classes of Antimicrobial Agents in Vitro. Journal of Medical Microbiology, 47, 1115-1122.

https://www.microbiologyresearch.org/docserver/fulltext/jmm/47/12/medmicro-47 -12-1115.pdf? expires $=1565590277 \& \mathrm{id}=\mathrm{id} \&$ accname $=$ guest $\&$ checksum $=737 \mathrm{~B} 6 \mathrm{C} 7 \mathrm{EF}$ 2B638462C05CD2B646414B7 https://doi.org/10.1099/00222615-47-12-1115

[128] Renaudin, H. and Bébéar, C. (1990) Comparative in Vitro Activity of Azithromycin, Clarithromycin, Erythromycin and Lomefloxacin against Mycoplasma pneumoniae, Mycoplasma hominis and Ureaplasma urealyticum. European Journal of Clinical Microbiology and Infectious Diseases, 9, 838-841.

https://link.springer.com/article/10.1007/BF01967388 https://doi.org/10.1007/BF01967388

[129] Roberts, M.C., Koutsky, L.A., Holmes, K.K., LeBlanc, D.L. and Kenny, G.E. (1985) Tetracycline-Resistant Mycoplasma hominis Strains Contain Streptococcal tetM Sequences. Antimicrobial Agents and Chemotherapy, 28, 141-143.

https://aac.asm.org/content/28/1/141

https://doi.org/10.1128/AAC.28.1.141

[130] Roberts, M.C. and Kenny, G.E. (1986) Dissemination of the tetM Tetracycline Resistance Determinant to Ureaplasma urealyticum. Antimicrobial Agents and Chemotherapy, 29, 350-352. https://aac.asm.org/content/29/2/350 https://doi.org/10.1128/AAC.29.2.350

[131] Bébéar, C.M., Renaudin, J., Charron, A., Renaudin, H., de Barbeyrac, B., Schaeverbeke, T. and Bébéar, C. (1999) Mutations in the gyrA, parC and parE Genes Associated with Fluoroquinolone Resistance in Clinical Isolates of Mycoplasma hominis. Antimicrobial Agents and Chemotherapy, 43, 954-956.

https://aac.asm.org/content/43/4/954 https://doi.org/10.1128/AAC.43.4.954

[132] Nicolson, G.L. (1998) Some Considerations When Undergoing Treatment for Chronic Illnesses and Autoimmune Diseases, plus Supplemental Suggestions. International Journal of Medicine, 1, 123-128.

http://www.immed.org/treatment\%20considerations/03.12.2012update/IMM.updat es\%2023.Sept.2018/Treatment\%20Considerations\%202018.pdf

[133] Nicolson, G.L., Nasralla, M.Y., Franco, A.R., Nicolson, N.L., Erwin, R., Ngwenya, R. and Berns, P.A. (2000) Diagnosis and Integrative Treatment of Intracellular Bacterial Infections in Chronic Fatigue and Fibromyalgia Syndromes, Gulf War Illness, Rheumatoid Arthritis and Other Chronic Illnesses. Clinical Practice of Alternative Medicine, 1, 92-102.

http://www.immed.org/Fatigue\%20Illness/06.08.12\%20pdfs/CPAM-GLNetal.-00.1.2 1RTF.pdf

[134] D’Alonzo, R., Mencaroni, E., Di Genova, L., Laino, D., Principi, N. and Esposito, S. (2018) Pathogenesis and Treatment of Neurological Diseases Associated with $M y-$ coplasma pneumoniae Infection. Frontiers in Microbiology, 9, Article 2751. 
https://www.frontiersin.org/articles/10.3389/fmicb.2018.02751/full https://doi.org/10.3389/fmicb.2018.02751

[135] Tilley, B.C., Alarcon, G.S., Heyse, S.P., Trentham, D.E., Neuner, R., Kaplan, D.A., Clegg, D.O., Leisen, J.C.C., Buckley, L., Cooper, S.M., Duncan, H., Pillemer, S.R., Tuttleman, M. and Fowler, S.E. (1995) Minocycline in Rheumatoid Arthritis: A 48-week, Double-Blind, Placebo-Controlled Trial. Annals of Internal Medicine, 122, 81-89. $\quad$ https://doi.org/10.7326/0003-4819-122-2-199501150-00001 https://annals.org/aim/article-abstract/708353/minocycline-rheumatoid-arthritis-48 -week-double-blind-placebo-controlled-trial

[136] Suzuki, S., Yamazaki, T., Narita, M., Okazaki, N., Suzuki, I., Andoh, T., Matsuoka, M., Kenri, T., Arakawa, Y. and Sasaki, T. (2006) Clinical Evaluation of Macrolide-Resistant Mycoplasma pneumoniae. Antimicrobial Agents and Chemotherapy, 50, 709-712. https://aac.asm.org/content/50/2/709 https://doi.org/10.1128/AAC.50.2.709-712.2006

[137] Todd, S.R., Dahlgren, F.S., Traeger, M.S., Beltrán-Aguilar, E.D., Marianos, D.W., Hamilton, C., McQuiston, J.H. and Regan, J.J. (2015) No Visible Dental Staining in Children Treated with Doxycycline for Suspected Rocky Mountain Spotted Fever. Journal of Pediatrics, 166, 1246-1251. https://www.jpeds.com/article/S0022-3476(15)00135-3/fulltext https://doi.org/10.1016/j.jpeds.2015.02.015

[138] Wang, M., Wang, Y., Yan, Y., Zhu, C., Huang, L., Shao, X., Xu, J., Zhu, H., Sun, X., Ji, W. and Chen, Z. (2014) Clinical and Laboratory Profiles of Refractory Mycoplasma pneumoniae Pneumonia in Children. International Journal of Infectious Diseases, 29, 18-23.

https://www.ijidonline.com/article/S1201-9712(14)01605-1/fulltext https://doi.org/10.1016/j.ijid.2014.07.020

[139] Bradshaw, C.R., Jensen, J.S. and Waites, K.B. (2017) New Horizons in Mycoplasma genitalium Treatment. Journal of Infectious Diseases, 216, S412-S419. https://www.ncbi.nlm.nih.gov/pmc/articles/PMC5853296/pdf/jix132.pdf https://doi.org/10.1093/infdis/jix132

[140] Chopra, I. and Roberts, M. (2001) Tetracycline Antibiotics: Mode of Action, Applications, Molecular Biology and Epidemiology of Bacterial Resistance. Microbiology and Molecular Biology Reviews, 65, 232-260.

https://mmbr.asm.org/content/65/2/232 https://doi.org/10.1128/MMBR.65.2.232-260.2001

[141] Butler, T. (2017) The Jarish-Herxheimer Reaction after Antibiotic Treatment of Spirochetal Infections: A Review of Recent Cases and Our Understanding of Pathogenesis. The American Journal of Tropical Medicine and Hygiene, 96, 46-52. https://www.ncbi.nlm.nih.gov/pmc/articles/PMC5239707/ https://doi.org/10.4269/ajtmh.16-0434

[142] Wormser, G.P., Dattwyler, R.J., Shapiro, E.D., Halperin, J.J., Steere, A.C., Klempner, M.S., Krause, P.J., Bakken, J.S., Strie, F., Stanek, G., Bockenstedt, L., Fish, D., Dumler, J.S. and Nadelman, R.B. (2006) The Clinical Assessment, Treatment and Prevention of Lyme Disease, Human Granulocytic Anaplasmosis and Babesiosis: Clinical Practice Guidelines by the Infectious Disease Society of America. Clinical Infectious Diseases, 43, 1089-1134.

https://academic.oup.com/cid/article/43/9/1089/422463

https://doi.org/10.1086/508667

[143] Lebeaux, D., Ghigo, J.-M. and Belion, C. (2014) Biofilm-Related Infections: Bridging the Gap between Clinical Management and Fundamental Aspects of Recalcitrance 
toward Antibiotics. Microbiology and Molecular Biology Reviews, 78, 510-543. https://www.ncbi.nlm.nih.gov/pmc/articles/PMC4187679/ https://doi.org/10.1128/MMBR.00013-14

[144] Lewis, K. (2006) Persister Cells, Dormancy and Infectious Disease. Nature Reviews Microbiology, 5, 48-56. https://www.nature.com/articles/nrmicro1557 https://doi.org/10.1038/nrmicro1557

[145] Fox, R.I. (1993) Mechanism of Action of Hydroxychloroquine as an Antirheumatic Drug. Seminars in Arthritis and Rheumatism, 32, 82-91. https://www.sciencedirect.com/science/article/abs/pii/S0049017210800125 https://doi.org/10.1016/S0049-0172(10)80012-5

[146] Lee, K.-Y., Lee, H.-S., Jong, J.-H., Lee, M.-H., Lee, J-S., Burgner, D. and Lee, B.-C. (2006) Role of Prednisolone Treatment in Severe Mycoplasma pneumoniae Pneumonia in Children. Pediatric Pulmonology, 41, 263-268.

https://onlinelibrary.wiley.com/doi/abs/10.1002/ppul.20374 https://doi.org/10.1002/ppul.20374

[147] Hughes, R.A., Swan, A.V. and van Doorn, P.A. (2014) Intravenous Immunoglobulins for Guillain-Barré Syndrome. Cochrane Database of Systematic Reviews, 2014, Article CD002063.

https://www.cochranelibrary.com/cdsr/doi/10.1002/14651858.CD002063.pub6/full? highlightAbstract=syndrom|guillain|withdrawn|barr|barre|syndrome https://doi.org/10.1002/14651858.CD002063.pub6

[148] Chevert, S., Hughes, R.A. and Annane, D. (2017) Plasma Exchange for Guillain-Barré Syndrome. Cochrane Database of Systematic Reviews, 2017, Article CD001798.

https://www.cochranelibrary.com/cdsr/doi/10.1002/14651858.CD001798.pub3/full? highlightAbstract=withdrawn|plasm|exchang|plasma https://doi.org/10.1002/14651858.CD001798.pub3

[149] Yrjänheikki, J., Tikka, T., Keinänen, R., Goldsteins, G., Chan, P.H. and Koistinaho, J. (1999) A Tetracycline Derivative, Minocycline, Reduces Inflammation and Protects against Focal Cerebral Ischemia with a Wide Therapeutic Window. Proceedings of the National Academy of Sciences of the United States of America, 96, 13496-13500. https://www.pnas.org/content/pnas/96/23/13496.full.pdf https://doi.org/10.1073/pnas.96.23.13496

[150] Tamaoki, J., Kadota, J. and Takizawa, H. (2004) Clinical Implications of the Immunomodulatory Effects of Macrolides. The American Journal of Medicine Supplements, 117, 5-11.

https://www.sciencedirect.com/science/article/abs/pii/S154827660400024X https://doi.org/10.1016/j.amjmed.2004.07.023

[151] Horowitz, R.I. (2017) How Can I Get Better? An Action Plan for Treating Resistant Lyme and Chronic Disease. St. Martin's Press, New York. https://us.macmillan.com/books/9781250070548

[152] Nicolson, G.L. and Ngwenya, R. (2001) Dietary Considerations for Patients with Chronic Illnesses and Multiple Chronic Infections. A Brief Outline of Eighteen Dietary Steps to Better Health. Townsend Letter, 219, 63-65.

http://www.immed.org/treatment\%20considerations/08.16.2012update/TownsendD ietConsid.-01.7.pdf

[153] Buhner, S.H. (2013) Healing Lyme Disease Coinfections. Complementary and Holistic Treatments for Bartonella and Mycoplasma. Healing Arts Press, Rochester. https://www.simonandschuster.com/books/Healing-Lyme-Disease-Coinfections/Ste phen-Harrod-Buhner/9781620550083 
[154] Anderson, C.J. (2015) Bioactive Eggs Components and Inflammation. Nutrients, 7, 7889-7913. https://www.mdpi.com/2072-6643/7/9/5372 https://doi.org/10.3390/nu7095372

[155] Nicolson, G.L. (2014) Mitochondrial Dysfunction and Chronic Disease: Treatment with Natural Supplements. Alternative Therapies in Health and Medicine, 20, 18-25.

http://www.immed.org/treatment\%20considerations/05.23.14.Treatment\%20Consi derations/Mito Dysfunct Treatm-NicolsonATHD2014.pdf

[156] Nicolson, G.L. (2014) Mitochondrial Dysfunction and Chronic Disease: Treatment with Natural Supplements. Integrative Medicine, 13, 35-43. https://www.ncbi.nlm.nih.gov/pmc/articles/PMC4566449/

[157] Dunstan, R.H., Sparkes, D.L., Roberts, T.K., Crompton, M.J., Gottfries, J. and Dascombe, B.J. (2013) Development of a Complex Amino Acid Supplement, Fatigue Reviva $^{\mathrm{TM}}$, or Oral Ingestion: Initial Evaluations of a Product Concept and Impact on Symptoms of Sub-Health in a Group of Males. Nutrition Journal, 12, Article No. 115.

https://www.ncbi.nlm.nih.gov/pmc/articles/PMC3751078/pdf/1475-2891-12-115.pd f https://doi.org/10.1186/1475-2891-12-115

[158] Schmidt, H.H.W., Stocker, R., Vollbracht, C., Paulsen, G., Riley, D., Daiber, A. and Cuadrado, A. (2015) Antioxidants in Translational Medicine. Antioxidants and Redox Signaling, 23, 1130-1143.

https://www.ncbi.nlm.nih.gov/pmc/articles/PMC4657516/pdf/ars.2015.6393.pdf https://doi.org/10.1089/ars.2015.6393

[159] Burri, B.J., La Frano, M.R. and Zhu, C. (2016) Absorption, Metabolism and Functions of Beta-Cryptoxanthin. Nutrition Reviews, 74, 69-82.

https://www.ncbi.nlm.nih.gov/pmc/articles/PMC4892306/pdf/nuv064.pdf https://doi.org/10.1093/nutrit/nuv064

[160] Nicolson, G.L., Ferreira de Mattos, G., Settineri, R., Costa, C., Ellithorpe, R., Rosenblatt, S., La Valle, J., Jimenez, A. and Ohta, S. (2016) Clinical Effects of Hydrogen Administration: From Animal and Human Diseases to Exercise Medicine. International Journal of Clinical Medicine, 7, 32-76. https://doi.org/10.4236/ijcm.2016.71005

[161] Ohsawa, I., Ishikawa, M., Takahashi, K., Watanabe, M., Nishimaki, K., Yamagata, K., Katsura, K., Katayama, Y., Asoh, S. and Ohta, S. (2007) Hydrogen Acts as a Therapeutic Antioxidant by Selectively Reducing Cytotoxic Oxygen Radicals. Nature Medicine, 13, 688-694. https://doi.org/10.1038/nm1577

[162] Kaufmann, G.F. and Schlievert, P.M. (2015) Non-Aqueous Glycerol Monolaurte Get Exhibits Antibacterial and Anti-Biofilm Activity against Gram-Positive and Gram-Negative Pathogens. PLoS ONE, 10, e120280. https://www.ncbi.nlm.nih.gov/pmc/articles/PMC4370562/pdf/pone.0120280.pdf https://doi.org/10.1371/journal.pone.0120280

[163] Theophilus, P.A.S., Victoria, M.J., Socarras, K.M., Filush, K.R., Gupta, K., Luecke, D.F. and Sapi, E. (2015) Effectiveness of Stevia rebaudiana Whole Leaf Extract against the Various Morphological Forms of Borrelia burgforferi in Vitro. European Journal of Microbiology and Immunology, 5, 268-280.

https://akademiai.com/doi/abs/10.1556/1886.2015.00031 https://doi.org/10.1556/1886.2015.00031

[164] Mirtaheri, E., Gargari, B.P., Kolahi, S., Dehghan, P., Asghari-Jafarabadi, M., Hajali- 
lou, M., Novin, Z.S. and Abbasi, M.M. (2015) Effects of Alpha-Lipoic Acid Supplementation on Inflammatory Biomarkers and Matrix Metalloproteinase-3 in Rheumatoid Arthritis Patients. Journal of the American College of Nutrition, 34, 310-317. https://www.tandfonline.com/doi/abs/10.1080/07315724.2014.910740 https://doi.org/10.1080/07315724.2014.910740

[165] Gareau, M.G., Sherman, P.M. and Walker, W.A. (2010) Probiotics and the Gut Microbiota in Intestinal Health and Disease. Nature Reviews of Gastroenterology and Hepatology, 7, 503-514.

https://www.ncbi.nlm.nih.gov/pmc/articles/PMC4748966/pdf/nihms338723.pdf https://doi.org/10.1038/nrgastro.2010.117

[166] Rondanelli, M., Faliva, M.A., Perna, S., Giacosa, A., Peroni, G. and Castellazzi, A.M. (2017) Using Probiotics in Clinical Practice: Where Are We Now? A Review of Existing Meta-Analyses. Gut Microbes, 8, 521-543.

https://www.ncbi.nlm.nih.gov/pmc/articles/PMC5730384/pdf/kgmi-08-06-1345414. pdf https://doi.org/10.1080/19490976.2017.1345414

[167] Surawicz, C.M. (2008) Role of Probiotics in Antibiotic-Associated Diarrhea, Clostridium difficile-Associated Diarrhea, and Recurrent Clostridium difficile-Associated Diarrhea. Journal of Clinical Gastroenterology, 42, S64-S70.

https://journals.lww.com/jcge/Abstract/2008/07001/Role of Probiotics in Antibio tic associated.5.aspx https://doi.org/10.1097/MCG.0b013e3181646d09

[168] Franzoso, G., Hu, P.C., Meloni, G.A. and Barile, M.F. (1994) Immunoblot Analyses of Chimpanzee Sera after Infection and after Immunization and Challenge with Mycoplasma pneumoniae. Infection and Immunity, 62, 1008-1014. https://iai.asm.org/content/62/3/1008

[169] Smith, C.B., Friedewald, W.T. and Chanock, R.M. (1967) Inactivated Mycoplasma pneumoniae Vaccine. Evaluation in Volunteers. JAMA, 199, 353-358. https://jamanetwork.com/journals/jama/article-abstract/663300 https://doi.org/10.1001/jama.1967.03120060051007

[170] Brown, R.C., Hendley, J.O. and Gwaltney Jr., J.M. (1972) Mycoplasma pneumonaie Vaccine: Antigenicity or Fubbered Antigens in Volunteers. Infection and Immunity, 5, 657-661. https://iai.asm.org/content/5/5/657

[171] Nicolson, G.L., Rosenblatt, S., Ferreira de Mattos, G., Settineri, R., Breeding, P.C., Ellithorpe, R.R. and Ash, M.E. (2016) Clinical Uses of Membrane Lipid Replacement Supplements in Restoring Membrane Function and Reducing Fatigue in Chronic Diseases and Cancer. Discoveries, 4, e54.

https://www.discoveriesjournals.org/discoveries/D.2016.01.PA-Dr Nicolson.pdf https://doi.org/10.15190/d.2016.1

[172] Nicolson, G.L. and Ash, M.E. (2017) Membrane Lipid Replacement for Chronic Illnesses, Aging and Cancer Using Oral Glycerolphospholipid Formulations with Fructooligosaccharides to Restore Phospholipid Function in Cellular Membranes, Organelles, Cells and Tissues. Biochimica et Biophysica Acta, 1859, 1704-1724. https://doi.org/10.1016/j.bbamem.2017.04.013

[173] Nicolson, G.L. (2016) Membrane Lipid Replacement: Clinical Studies Using a Natural Medicine Approach to Restoring Membrane Function and Improving Health. International Journal of Clinical Medicine, 7, 133-143.

http://www.scirp.org/Journal/PaperInformation.aspx?PaperID=63602

https://doi.org/10.4236/ijcm.2016.72015 
[174] Nicolson, G.L., Settineri, R., Ferreira, G. and Breeding, P. (2018) Reduction of Pain, Fatigue, Gastrointestinal and Other Symptoms and Improvement in Quality of Life Indicators in Fibromyalgia Patients with Membrane Lipid Replacement Glycerolphospholipids and Controlled-Release Caffeine. International Journal of Clinical Medicine, 9, 560-579.

https://www.scirp.org/Journal/PaperInformation.aspx?PaperID=86236 https://doi.org/10.4236/ijcm.2018.97051 